Nat. Hazards Earth Syst. Sci., 18, 2741-2768, 2018

https://doi.org/10.5194/nhess-18-2741-2018

(C) Author(s) 2018. This work is distributed under

the Creative Commons Attribution 4.0 License.

\title{
Epistemic uncertainties and natural hazard risk assessment - Part 1: A review of different natural hazard areas
}

Keith J. Beven ${ }^{1,2}$, Susana Almeida ${ }^{3}$, Willy P. Aspinall ${ }^{4}$, Paul D. Bates ${ }^{5}$, Sarka Blazkova ${ }^{6}$, Edoardo Borgomeo ${ }^{7}$, Jim Freer ${ }^{5}$, Katsuichiro Goda ${ }^{3}$, Jim W. Hall ${ }^{7}$, Jeremy C. Phillips ${ }^{4}$, Michael Simpson ${ }^{7}$, Paul J. Smith ${ }^{1,8}$, David B. Stephenson ${ }^{9}$, Thorsten Wagener ${ }^{3,10}$, Matt Watson ${ }^{4}$, and Kate L. Wilkins ${ }^{4}$

${ }^{1}$ Lancaster Environment Centre, Lancaster University, Lancaster, UK

${ }^{2}$ Department of Earth Sciences, Uppsala University, Uppsala, Sweden

${ }^{3}$ Department of Civil Engineering, Bristol University, Bristol, UK

${ }^{4}$ School of Earth Sciences, Bristol University, Bristol, UK

${ }^{5}$ School of Geographical Sciences, Bristol University, Bristol, UK

${ }^{6}$ T. G. Masaryk Water Resource Institute, Prague, Czech Republic

${ }^{7}$ Environmental Change Institute, Oxford University, Oxford, UK

${ }^{8}$ Waternumbers Limited, Halton Mill, Halton, Lancaster, LA2 6DN, UK

${ }^{9}$ Department of Mathematics and Computer Science, Exeter University, Exeter, UK

${ }^{10}$ Cabot Institute, University of Bristol, Bristol, UK

Correspondence: Keith J. Beven (k.beven@lancaster.ac.uk)

Received: 6 July 2017 - Discussion started: 21 August 2017

Revised: 7 September 2018 - Accepted: 24 September 2018 - Published: 24 October 2018

\begin{abstract}
This paper discusses how epistemic uncertainties are currently considered in the most widely occurring natural hazard areas, including floods, landslides and debris flows, dam safety, droughts, earthquakes, tsunamis, volcanic ash clouds and pyroclastic flows, and wind storms. Our aim is to provide an overview of the types of epistemic uncertainty in the analysis of these natural hazards and to discuss how they have been treated so far to bring out some commonalities and differences. The breadth of our study makes it difficult to go into great detail on each aspect covered here; hence the focus lies on providing an overview and on citing key literature. We find that in current probabilistic approaches to the problem, uncertainties are all too often treated as if, at some fundamental level, they are aleatory in nature. This can be a tempting choice when knowledge of more complex structures is difficult to determine but not acknowledging the epistemic nature of many sources of uncertainty will compromise any risk analysis. We do not imply that probabilistic uncertainty estimation necessarily ignores the epistemic nature of uncertainties in natural hazards; expert elicitation for example can be set within a probabilistic framework to do just that. However, we suggest that the use of simple aleatory distri-
\end{abstract}

butional models, common in current practice, will underestimate the potential variability in assessing hazards, consequences, and risks. A commonality across all approaches is that every analysis is necessarily conditional on the assumptions made about the nature of the sources of epistemic uncertainty. It is therefore important to record the assumptions made and to evaluate their impact on the uncertainty estimate. Additional guidelines for good practice based on this review are suggested in the companion paper (Part 2).

\section{Introduction}

With the increasing appreciation of the limitations of traditional deterministic modelling approaches, uncertainty estimation has become an increasingly important part of natural hazards assessment and risk management. In part, this is a natural extension of the evaluation of frequencies of hazards in assessing risk, in part an honest recognition of the limitations of any risk analysis, and in part because of the recognition that most natural hazards are not stationary in their frequencies of occurrence. 


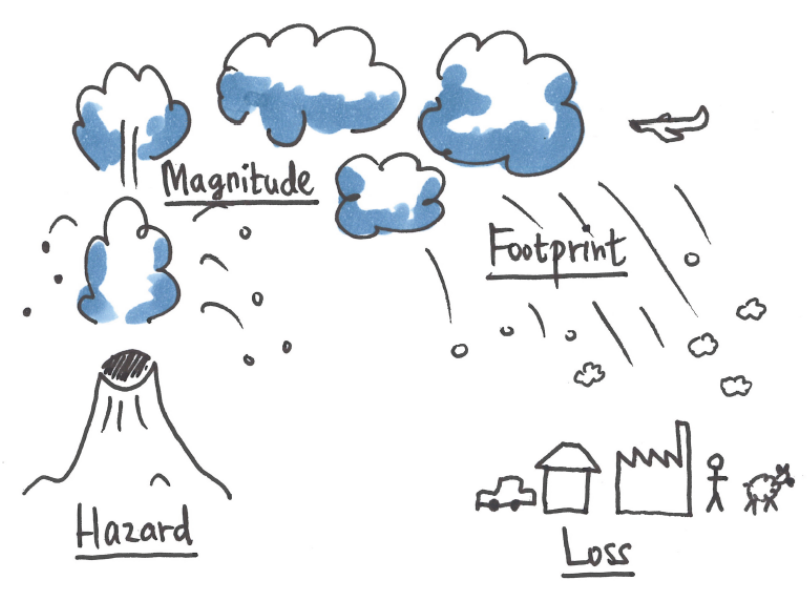

Figure 1. Hazard-magnitude-footprint-loss, illustrated by an ashy volcanic eruption (@ Jonty Rougier).

The consideration of uncertainty in risk assessments has, however, been relatively uncommon, particularly in respect to the epistemic uncertainties, i.e. those that are not well determined by historical observations and therfore represent gaps in knowledge. In this review we discuss the impact of epistemic uncertainties on risk assessment and management for different types of natural hazards. Throughout, we believe it is important to think about the full hazard-magnitudefootprint-loss setting (e.g. Rougier et al., 2013), which may be stakeholder specific (Fig. 1). This means that any risk assessment involves a modelling cascade, each element of which involves epistemic uncertainties, with the potential for the uncertainty in risk to grow, or be constrained by additional data, within each component in the cascade (e.g. Beven and Lamb, 2014).

Probabilistic risk analyses typically assume - even though they do not have to - that the different sources of uncertainty can, at some fundamental level, be treated as random or aleatory variables (and that all possible futures have been considered so that the probability assessments can be taken as complete). There is, however, an increasing appreciation that this is not the only type of uncertainty that arises in such analyses across natural hazard areas (Hoffman and Hammonds, 1994; Helton and Burmaster, 1996; Walker et al., 2003; Brown, 2004, 2010; Van der Sluijs et al., 2005; Wagener and Gupta, 2005; Refsgaard et al., 2006, 2007, 2013; Beven, 2009, 2012, 2013, 2016; Warmink et al., 2010; Stein et al., 2012; Rougier and Beven, 2013; Beven and Young, 2013; Simpson et al., 2016; Mulargia et al., 2017; Almeida et al., 2017). In particular, since the time of Keynes (1921) and Knight (1921), it has been common practice to distinguish between those uncertainties that might be represented as random chance, and those which arise from a lack of knowledge about the nature of the phenomenon being considered. Knight (1921) referred to the latter as the "real uncertain- ties" and they are now sometimes called "Knightian uncertainties". While Knight's thinking predated modern concepts and developments in probability theory (e.g. de Finetti, 1937, 1974; Cox, 1946), the distinction between uncertainties that can be treated simply as aleatory and as additional knowledge uncertainties holds.

An argument can be made that all sources of uncertainty can be considered as a result of not having enough knowledge about the particular hazard occurrence being considered: it is just that some types of uncertainty are more acceptably represented in terms of probabilities than others. In current parlance, these are the "aleatory uncertainties" while the Knightian real uncertainties are the "epistemic uncertainties". Aleatory uncertainties represent variability, imprecision and randomness, or factors that can be modelled as random for practical expediency, which can be represented as forms of noise within a statistical framework. Within epistemic uncertainties it is possible to subsume many other uncertainty concepts such as ambiguity, reliability, vagueness, fuzziness, greyness, inconsistency, and surprise that are not easily represented as probabilities.

This distinction is important because most methods of decision-making used in risk assessments are based on the concept of risk as the product of a probability of occurrence of an event (the hazard, magnitude and footprint components in the model cascade) and an evaluation of the consequences of that event (the loss component). If there are important uncertainties in the assessment of the occurrence that are not easily assessed as probabilities, or if there are significant epistemic uncertainties about the consequences, then some other means of assessing risk decisions might be needed. Given the lack of knowledge, there is also plenty of opportunity for being wrong about the assumptions used to describe sources of uncertainty or having different belief systems about the representations of uncertainties (e.g. Marzocchi and Jordan, 2014; Beven, 2016); hence testing the impact of the assumptions and choices made is becoming increasingly important (Pianosi et al., 2016). Epistemic uncertainties are also sometimes referred to as "deep uncertainties" in risk analysis and natural hazards (e.g. Cox Jr., 2012; Stein and Stein, 2013).

For the practical purposes of this review, we will define epistemic uncertainty as those uncertainties that are not well determined by historical observations. This lack of determination can be because the future is not expected to be like the past or because the historical data are unreliable (imperfectly recorded, estimated from proxies, or missing); because they are scarce (because measurements are not available at the right scale or long enough period); because the structure of that uncertainty does not have a simple probabilistic form; or because we expect the probability estimates to be incomplete (unbounded or indeterminable, e.g. Brown, 2004).

In what follows we consider the key sources and impact of epistemic uncertainties in different natural hazard areas. We also recognize that different types of hazard mitigation strat- 
egy might have different sensitivities to the treatment of epistemic uncertainties (e.g. Day and Fearnley, 2015). We see the typical audience of this opinion piece as a natural hazard scientist who is likely aware of uncertainties in his/her own specific hazard area, while having a limited understanding of other hazard areas and of the approaches available to deal with epistemic uncertainties. Our aim is to discuss how epistemic uncertainties have been recognized and treated in the different hazard areas, to bring out some commonalities and differences. It is difficult to go into great detail on each aspect covered here; hence the focus is on providing an overview and on citing key literature. In the second part of the paper we discuss the different opinions about the options for addressing epistemic uncertainty and we discuss open problems for implementing these options in terms of what might constitute good practice (Beven et al., 2018).

\section{Floods}

\subsection{Floods and key epistemic uncertainties}

Floods account for about one-third of all economic losses from natural hazards globally (UNISDR, GAR 2015). The frequency and magnitude of flood disasters is likely to increase with a warming atmosphere due to climate change and with increased exposure of a growing population (Winsemius et al., 2016), which suggests that the fractional contribution to global disaster losses is likely to increase even further. There are five aspects of flood risk assessment that involve important epistemic uncertainties. The first is the assessment of how much rainfall or snowmelt input occurs (either in past or future events); the second is the frequency with which such events might occur and how that might be changing; the third is how much of that input becomes flood runoff; the fourth is the footprint of the flood inundation; and the fifth is the assessment of either past or potential damages (see discussion in Sect. 11 below). These all apply in the assessment of expected damages for events of different magnitude for making decisions in managing the flood risk and in the management of flood incidents in real time (e.g. Sayers et al., 2002).

\subsection{Uncertainty quantification in flood hazard estimation}

In the context of flooding, uncertainties in inputs and runoff generation are often avoided by estimating the probability of exceedance for different magnitudes of event in terms of an extreme value distribution of discharges. That does not mean that such uncertainties are not important (such as lack of knowledge about the effects of a poorly known spatial pattern of inputs on runoff generation, the role of antecedent conditions in controlling runoff generation, or estimates of historical flood peak discharges), only that they are assumed to contribute to some underlying statistical distribution of events that is fitted to the available historical data. This pro- vides estimates of frequency as if the series of historical floods is drawn from a stationary distribution, which is not easily modified to allow for future change (e.g. Prudhomme et al., 2010).

The epistemic uncertainty is then convolved into a question of what statistical distribution should be used. This question has often been resolved by institutionalizing the uncertainty into a particular choice of standard distribution. Different countries have chosen different distributions and, in some cases, have changed that choice over time. There are good theoretical reasons to choose the generalized extreme value (GEV) distribution. Asymptotically a sample of extremes with independent occurrences in successive time periods (e.g. years) from an arbitrary underlying distribution of events should have the form of the GEV distribution. It was the distribution of choice for the analysis of annual maximum floods in the UK Flood Studies Report (NERC, 1975). However, the time series available for the analysis of floods are often relatively short, so the asymptotic condition may not be approached, and the occurrences of events may not be independent in time or space (e.g. Eastoe and Tawn, 2010; Keef et al., 2013). Thus, in revising the UK methodology in the Flood Estimation Handbook, a change was made to recommend the Generalized Logistic Distribution as it resulted in fewer sites being assigned parameters that suggested some upper limit to flood magnitudes (IH, 1999). Many other distributions have been used elsewhere. A recent development in flood risk management has been concerned with the joint occurrences of flood events, rather than looking at individual sites independently. This requires specifying not only one distribution but joint distributions and the correlation structure between them (e.g. Keef et al., 2013), but which may not be well defined by historical data.

The choice of a particular distribution essentially controls the form of the upper tail of the distribution and consequently the assessment of risk. This is common to the other natural hazards that are considered below. Good practice suggests that the statistical uncertainty associated with the tail of the fitted distribution should be evaluated (although this is rarely reported even where it is provided by the analysis software), but essentially we have additional epistemic uncertainties as to which distribution to choose and whether to treat that distribution as stationary or whether clusters of events might come from some more complex stochastic structure (e.g. Koutsoyiannis, 2003, 2010; Montanari and Koutsoyiannis, 2012). If this is the case, then it might result in a significant increase in the range of uncertainty relative to classical statistical analysis (e.g. Koutsoyiannis and Montanari, 2007) irrespective of other sources of epistemic uncertainty.

These issues have led some people to return to considering the inputs and runoff generation over a catchment more directly in flood risk estimation. This approach was pioneered by Eagleson (1972) using a simple derived distribution model of runoff generation, but increased computer power has allowed continuous simulation over long periods of time us- 
ing rainfall-runoff models, which has the advantage that the variation in antecedent wetness of a catchment prior to an event is part of the simulation (e.g. Beven, 1987; Cameron et al., 1999, 2000; Lamb and Kay, 2004; Blazkova and Beven, 2004, 2009; Wagener et al., 2004). In some cases it is possible to use long series of observed rainfall data to simulate discharges, but for the very long series that are needed to estimate more extreme events it is necessary to use a stochastic model of the inputs (similar to the weather generators used to produce future sequences in climate change impact assessments). However, this only shifts the epistemic uncertainty issue of the choice of appropriate distributions or more complex stochastic structures for the space-time characteristics of rainfall (e.g. Chandler et al., 2014). The extreme events generated from such a weather generator depend on the tails of the assumed distribution(s) and there will again be epistemic uncertainty about what type of distribution to use, even where rainfall series are longer than discharge records.

A further advantage of the continuous simulation approach is that the weather generator can be modified to represent future climates (e.g. Cameron et al., 2000; Wilby and Dessai, 2010; Prudhomme and Davies, 2009; Prudhomme et al., 2010), and that input data might be more readily available for sites for which there are no discharge records (the prediction in ungauged basins problem, Wagener et al., 2004; Blöschl et al., 2013; Hrachowitz et al., 2013). This latter case still requires that the parameters of a rainfall-runoff model be specified. This is also an epistemic uncertainty issue, even if extrapolations from gauged sites are often made using statistical regression or pooling group methods (e.g. Lamb and Kay, 2004); a process that will be influenced by model structural uncertainty and other uncertainty sources (e.g. McIntyre et al., 2005; Wagener and Wheater, 2006). Experience in predicting the flood characteristics in this way has been somewhat mixed; successful in some basins, but with significant over or underestimation in others (Lamb and Kay, 2004; Blöschl et al., 2013). Improvements to such methods might still be possible but epistemic uncertainty will remain a constraint on accuracy.

Further uncertainties arise in the estimation of the footprint of the flood event. There may be different areas at risk of inundation according to whether the risk is from pluvial, fluvial, coastal, or groundwater flooding. By making assumptions about various sources of uncertainty in the modelling of inundation, a (Monte Carlo based) forward uncertainty analysis can be used to predict uncertainties in inundation areas and depths (e.g. Berry et al., 2008). In some cases, historical flood mapping is available that can be used to condition hydraulic models of inundation and constrain the uncertainty in model predictions (Bates et al., 2014). The generalized likelihood uncertainty estimation (GLUE; Aronica et al., 1998; Romanowicz and Beven, 2003; Pappenberger et al., 2007; Neal et al., 2013; Beven et al., 2014; Beven and Lamb, 2014) and more formal Bayesian methods (Romanowicz et al., 1996; Hall et al., 2011) have both been used in this type

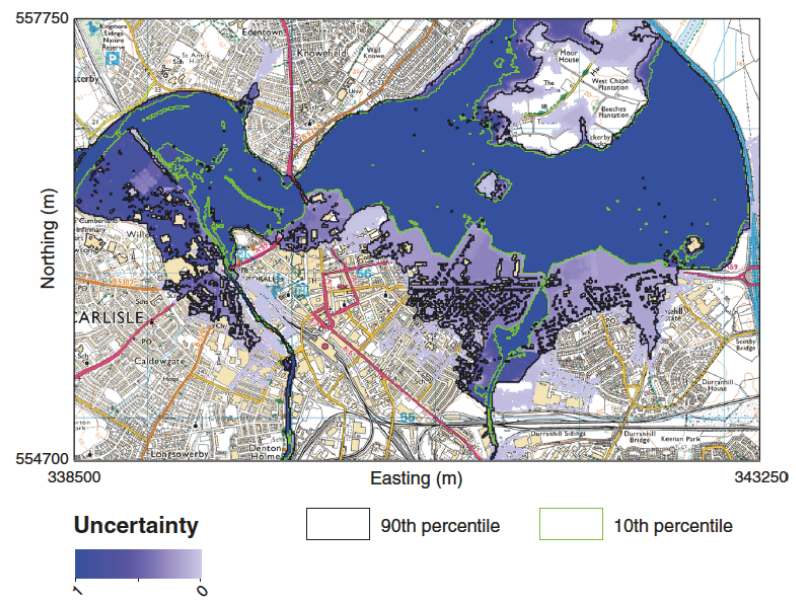

Figure 2. Uncertainty in inundation extent resulting from simulations of the flood with annual exceedance probability of 0.01 , river Eden valley in the vicinity of Carlisle, Cumbria, UK. The uncertainty scale results from a behavioural ensemble of LISFLOOD-FP inundation models with different parameters sets, weighted according to fit to the 2005 flood outline, and driven by realizations from the joint distribution of peak discharges in the river Eden and the Caldew and Petteril tributaries (from full details see Neal et al., 2013).

of conditioning process (e.g. Fig. 2; see also other examples in Beven et al., 2014).

Recent improvements in flood inundation modelling have been less a result of reducing uncertainties in inputs and hydraulic parameters, but rather due to reductions in uncertainties in topography as lidar surveys have become more widely available or in land surface properties through remotely sensed information (e.g. Wood et al., 2016). However, lidar cannot identify all the barriers to flow on a flood plain (e.g. Sampson et al., 2012). A further issue can be that effective hydraulic parameters identified for one magnitude of event might not hold for a larger magnitude event (e.g. Romanowicz and Beven, 2003), which would introduce epistemic uncertainty. It is also common to assume that the effective parameters are spatially constant which, when interacting with other sources of uncertainty, might mean that it is not possible to get good fits for inundation observations everywhere in the modelled domain (e.g. Pappenberger et al., 2007; Savage et al., 2016).

In many situations, flooding is constrained by the existence of natural levees or artificial flood defences. Such defences are always associated with a residual risk of being overtopped and/or failing, a risk that will vary due to factors including construction methods, programme of maintenance, and unauthorized modifications (van Gelder and Vrijling, 2014). These are all subject to epistemic uncertainties but are often dealt with through using fragility curves that give a probability of failure as a function of water level (e.g. Lamb et al., 2017). Although expressed in terms of probabil- 
ities, such fragility curves are often treated as deterministically known (Gouldby et al., 2010).

\subsection{Uncertainty quantification in real-time flood management}

In flood incident management, epistemic uncertainties might lead to deterministic predictions being biased, even where models of flood discharges and extent of inundation have been calibrated for past events. This is usually handled in one of two ways. Traditionally it was handled by the experience and expertise of the flood forecasters who would make subjective adjustments to model outputs available to them as an event progressed and more information became available. In doing so they would qualitatively allow for perceived epistemic uncertainties based on past experience. This approach is still used in many countries. An extension of this approach is to base estimates of the uncertainty in model predictions based on the performance of the model in past events. A method such as quantile regression can be used for this situation (López López et al., 2014). The problem for both approaches is that past experience may not be a good guide to the peculiarities of a new event.

A different strategy is to assume that all uncertainties can be treated statistically and use a data assimilation approach to correct for over or under-prediction as the event proceeds. Techniques such as the Kalman filter, or stochastic autoregressive modelling, can be used with the advantage that an estimate of the variance of the forecast can also be updated at the same time (see, for example, Sene et al., 2014; Young et al., 2014; Smith et al., 2012, 2013a). No explicit account of potential epistemic uncertainties is normally made in this approach; the aim is only to improve the forecast and minimize the forecast variance at the required lead time as new data become available for assimilation. The approach will often work well when the required lead time is less than the response time of the upstream catchment so that the data assimilation can rely on measured inputs. It works less well in flash flood situations in small catchments with short response times so that forecasts of the inputs are needed to produce a forecast with reasonable response time (Alfieri et al., 2011; Smith et al., 2013b; Yatheendradas et al., 2008). Rainfall forecasts from numerical weather prediction (NWP) models are still not sufficiently accurate for this purpose but are now used routinely (such as in the European Flood Awareness System hosted at ECMWF, Bartholmes et al., 2009; De Roo et al., 2011) for providing flood alerts some days ahead.

\subsection{Floods and the safety of dams}

The safety of dams is an interesting example of a hazard that involves both natural forcing and engineering design, but one in which the consequences of failure can be catastrophic. Lists of dam failures (e.g. Vogel, 2001) show that such events are not common, but the International Commission on Large
Dams (ICOLD, 1995) has estimated that some $0.5 \%$ of all dams failed in the period 1951-1986. The most fatalities estimated are for the failure of several dams in Henan Province in China in 1975 which killed an estimated 171000 people and destroyed the houses of 11 million people.

Multiple causes that are subject to epistemic uncertainties (e.g. hydrological forcing, landslides upstream, poor design, or poor maintenance) make dam failures difficult to predict, and most countries take a highly precautionary approach to regulating for dam safety. Dams and spillway channels for large dams are commonly designed to cope with the estimate of the flood with an annual exceedance probability of 0.0001 . This is a much smaller probability than for designing normal flood defences, because of the potential consequences of a failure, but means that such estimates are dependent on epistemic uncertainties in estimating such tail probabilities. In addition, the greatest forcing might not come from the highest flood peak if it is of short duration, but from the inflow volume associated with an event of longer duration but smaller peak. One way of assessing such effects is to run a continuous simulation model and examine the impact of the most extreme events generated over with long realizations (e.g. Blazkova and Beven, 2009). The continuous simulation approach means that the antecedent conditions prior to any event are handled naturally, but clearly the outputs from such simulations are dependent on the epistemic uncertainties associated with all the model components, including the tail assumptions for the driving distributions, the choice of rainfallrunoff model, and the estimation of model parameters given the historical data.

Predicting the downstream footprint of a dam failure and the consequent threat to life and potential damage can also be difficult. There are hydraulic models available designed to cope with the high discharges and sharp wave fronts expected with a dam failure (Cao et al., 2004; Xia et al., 2010), but the application in any real case study will depend on the epistemic uncertainty associated with the characteristics of a breach in the dam acting as an upstream boundary condition for the hydraulic model and the momentum losses in the downstream area as a highly sediment-laden fluid interacts with the valley bottom infrastructure and vegetation. It is also difficult to verify the outputs of such a model (though see Hervouet and Petitjean, 1999; Begnudelli and Sanders, 2007; and Gallegos et al., 2009; for examples of field scale validation), while predictions of velocities, as well as depths, will be important in assessing the consequences.

\section{Landslides and debris flows}

\subsection{Landslides and key epistemic uncertainties}

Globally, landslides are directly responsible for several thousand deaths per year (Petley, 2012). A widely cited example is that of the Welsh village of Aberfan, where a flowslide 
from a colliery spoil tip killed 144 people, 116 of whom were children, at the Pantglas Junior School in October 1966 (Johnes, 2000). More recently, the Gansu mudslide, which occurred after heavy rain in August 2010 in China, killed an estimated 1765 people. However, despite the large risks posed by landslides, the ability of research to guide and inform management decisions is limited by high levels of uncertainty in model assessments of slope stability. In landslide risk assessment epistemic uncertainties arise from a range of sources, including errors in measurement data, gaps in the understanding of landslide processes and their representation in models, and from uncertain projections of future socioeconomic and biophysical conditions (Lee and Jones, 2004).

\subsection{Uncertainty quantification in landslide hazard estimation}

Landslide risk can be assessed qualitatively or quantitatively. The choice depends on the scale of work (national, regional, local or site-specific), and also on the quality and quantity of data available. For site-specific slopes, physically based deterministic models centred on slope stability analysis are commonly used to assess the probability of landslide occurrence. Stability conditions are generally evaluated by means of limit equilibrium methods, where the available soil strength and the destabilizing effect of gravity are compared in order to calculate a measure of the relative stability of the slope known as the factor of safety. The limit equilibrium method relies on significant simplifications, such as that the failing soil mass is rigid, the failure surface is known, and the material's failure criterion is verified for each point along this surface. These simplifications limit both accuracy and applicability. Epistemic uncertainties related to the limited understanding of system processes and functioning can lead to large errors in such model predictions. For example, in 1984, an embankment dam in Carsington, England, slipped, despite the fact that limit equilibrium analysis had indicated that the slope was not expected to be at risk of failure. This discrepancy has been shown to be caused by epistemic errors, as brittle soils may exhibit strain-softening behaviour when loaded, leading to progressive failure, a phenomenon which cannot be reproduced using conventional limit equilibrium stability analyses. For this type of soil, finite element analysis using appropriate numerical algorithms and constitutive models are required to achieve a more accurate prediction of stability, which means that better accounting of process uncertainty can sometimes be remedied by more detailed modelling (Potts et al., 1990).

All physically based slope stability models are subject to epistemic uncertainties in both the constitutive relationships chosen and the parameter values required by those relationships. Parameter variability is often assessed by making small scale laboratory measurements of parameters, such as cohesion and coefficient of friction but the resulting values may not be directly applicable on a large scale because of the effects of spatial heterogeneities, and additional factors such as root strength (Christian et al., 1994; Rubio et al., 2004; Hall et al., 2004; Hürlimann et al., 2008; Hencher, 2010). Although spatial variability of soil properties has been recognized as an important source of epistemic uncertainty in the literature (e.g. El-Ramly et al., 2002; Griffiths and Fenton, 2004), it has often been ignored in previous analyses using limit equilibrium methods. The use of constant values for soil properties over soil deposits may lead to unreliable estimates of the probability of failure of a slope (El-Ramly et al., 2002; Griffiths and Fenton, 2004; Cho, 2007; Griffiths et al., 2009). To account for this source of uncertainty in slope stability problems, some investigators combine limited equilibrium methods with random field theory (e.g. Cho, 2007). Random field theory allows soil properties to be described by a randomly generated distribution, instead of a single value across the entire modelled space.

The finite-element method has the added advantage of being capable of simulating water flow and coupled hydromechanical behaviour under saturated and unsaturated conditions (Alonso et al., 2003; Gens, 2010). Time-varying boundary conditions to simulate the effect of rainfall and vegetation can be used (e.g. Nyambayo and Potts, 2010). Even at sites where the costs of extensive field investigations can be justified, there is much that remains unknown about the subsurface, including the detail of water flow pathways and knowledge of the hydromechanical behaviour of soils. Understanding the trade-off between data support, model complexity, and predictive uncertainty is therefore crucial.

To accommodate uncertainty caused by parameter variability in both limit equilibrium and finite-element methods of analysis, Monte Carlo simulation and/or the first-ordersecond-moment (FOSM) method are commonly used (e.g. Christian et al., 1994; Wu and Abdel-Latif, 2000; Haneberg, 2004; Cho, 2007). These methods consider the uncertainties introduced by the inputs in different ways. Monte Carlo simulation starts by repeatedly sampling from the probability distributions of the random variables. A deterministic computation on each of generated input set is performed and the factor of safety is calculated. Subsequently, the aggregated results of all sets provide an approximation of the probability distribution of the factor of safety. Alternatively, the FOSM method can be used to estimate the probability of slope failure. This probabilistic method determines the stochastic moments of the performance function. As the input variables are randomly distributed, the performance function is also randomly distributed, which the FOSM method characterizes in terms of its mean and standard deviation. In both methods, therefore, the uncertain parameters are treated as aleatory variables.

Detailed slope stability models require geotechnical information on site conditions that can be prohibitively costly to obtain and so tend to be employed only in small areas for cases where high risk is anticipated, while simpler strategies might suffice in many straightforward cases. Over 
large and complex areas, where the use of detailed physically based models is not feasible, statistical and data-driven models relating the probability of spatial landslide occurrence (i.e. susceptibility) and local geo-environmental conditions (e.g. geological, topographical and land-cover conditions) are used instead (e.g. Guzzetti et al., 1999, 2005, 2006; Ercanoglu and Gokceoglu, 2002). These models have become standard in landslide susceptibility assessment at a regional scale (Corominas et al., 2014). By estimating where the slope is most likely to fail (but not the recurrence of failure, i.e. the temporal frequency or magnitude of the expected landslide), these models can be of great help in land-use planning, guiding planners in the delimitation of suitable areas for future development. Guzzetti et al. (2006), for example, established for the Collazzone area, Italy, a landslide susceptibility model through discriminant analysis by finding a combination of predictor variables that maximizes the difference between the populations of stable and unstable slopes with minimal error. The generalization of a very complex problem into a relatively simple statistical model, necessarily introduces errors in model predictions, arising from errors in the predictors used to establish the model, uncertainty in the classification of the terrain units, etc.

Despite the above discussed limitations of more complex models for landslide risk studies, computational advancements do make the use of mechanistic models more feasible for future applications - even when considering uncertainty and when running the model over regional scales. Almeida et al. (2017) demonstrated this possibility by applying the widely used CHASM model (Holcombe et al., 2012) within a Monte Carlo (MC) framework. The MC framework allowed for the consideration of uncertainties due to poorly defined geophysical slope properties, which is particularly problematic for developing regions such as the study's Caribbean island location where data support is poor, but hazard risk is especially high. More importantly, Almeida et al. (2017) demonstrated how epistemic uncertainty can be considered as well. The uncertainty considered originated from a lack of knowledge about how intensity-duration-frequency (IDF) curves might vary under future climate change. Such IDF curves provide the design rainfall used by engineers in slope failure risk assessments. Almeida et al. (2017) used a bottomup approach in which (in this case) a classification and regression tree (CART) was developed to identify how much the design rainfall has to change before specific slopes become significantly more likely to fail (for a more general discussion of such an approach see Ray and Brown, 2015). Hence, while future rainfall intensities are unknown, this information still enables engineers to assess which slopes are at a higher risk of being impacted than others.

Another large source of uncertainty affecting the assessment of landslide susceptibility is often introduced by the unavoidable imprecision with which experts approach a problem, given limited information. To account for the uncertain and inexact character of the available information and for the possibility of limited information concerning a real system, fuzzy-based risk assessment models have been suggested in the literature (e.g. Ercanoglu and Gokceoglu, 2002; Lin et al., 2012). For example, based on a landslide inventory database, Ercanoglu and Gokceoglu (2002) applied factor analysis to determine the important weights of the factors conditioning landslides in the area (slope angle, land use, topographical elevation, dip direction of movement, water conditions, and weathering depth). Fuzzy-set theory is then applied, accounting for the judgemental uncertainty (fuzziness, vagueness, imprecision) introduced by the way experts approach the problem. In a rule-based fuzzy model, the fuzzy prepositions are represented by an implication function (e.g. "If slope angle is very low then landslide susceptibility is nonsusceptible") commonly called fuzzy if-then rules or fuzzy conditional statements. The fuzzy if-then rules are then used to produce a fuzzified index map for each factor conditioning landslides. These maps are thereafter combined (by overlaying) to produce a landslide susceptibility map.

In the context of long-term landslide risk management, as for other natural hazards fields, such as floods or earthquakes, the probability of exceedance is often calculated for different sizes of events in terms of an extreme value distribution. This approach has advantages over a simulation-based analysis, the results of which may be affected by uncertainties in input forcing data. However, this does not mean that uncertainties in factors contributing to landslides are ignored in probabilistic estimates of landslide risk. Instead, probabilistic estimates implicitly account for input uncertainty by fitting a statistical distribution of events to available historical data. As in the case of floods, the epistemic uncertainty is convolved into a question of what statistical distribution should be used and how uncertainty in the tail behaviour is estimated. Probabilistic models such as binomial model, Poisson model (Crovelli, 2000) and the power-law distribution (Hungr et al., 1999; Dussauge-Peisser et al., 2002) have been suggested in the literature to estimate the frequency (or return period) of landslides of a given size.

\subsection{Uncertainty quantification in real-time landslide warning systems}

In the context of real-time warning systems, slope failure is commonly estimated by establishing landslide-triggering thresholds of the initiating agent. The application of triggering thresholds has been used, for example, in early warning systems in areas prone to rainfall-induced landslides, by establishing relationships between landslide occurrence and rainfall indicators, such as antecedent rainfall, duration, intensity and cumulative rainfall (Aleotti, 2004; Cepeda et al., 2012). An empirical model between rainfall and landslide initiation has been used to issue warnings during the storms of 12 to 21 February 1986 in the San Francisco Bay Area (Keefer et al., 1987). Since information regarding data quality is often lacking, one common way to deal with uncer- 
tainty involves tracing the rainfall threshold curves that correspond to different percentiles and then deciding on a minimum threshold satisfying some performance criterion (e.g. rainfall threshold curve established so that includes $90 \%$ of the historical events; Aleotti, 2004). Nevertheless, epistemic uncertainty introduced by lack of knowledge on landslide occurrence can be significant. For example, Gariano et al. (2015) show that even a small $(1 \%)$ underestimation in the number of the considered landslides can result in a significant decrease in performance of an early warning system.

\section{Droughts}

\subsection{Droughts and key epistemic uncertainties}

Drought has the potential to cause widespread fatality and economic damage, particularly when a drought event might last for years or even decades (van Loon et al., 2016a, b). As with floods, droughts may be characterized either in terms of their natural severity or their impacts. The definition of drought depends on the type of water deficit being considered (rainfall, stream flow etc.). Drought follows the hydrological cycle, as precipitation deficits (meteorological droughts) lead to low soil moisture levels (agricultural/soil drought) and decreased river flows (hydrological drought) which in turn may lead to lowering of reservoir levels and water shortages (socioeconomic drought). Drought periods associated with high temperatures may also have cascading impacts such as the large number of excess deaths in Europe in the summer of 2003 (Robine et al., 2008). Unlike many other hazards, droughts other than in their most meteorological definitions are co-creations of human and environmental effects, in which the hazard-footprint-loss chain is non-linear. Epistemic uncertainties in drought risk assessments stem from unknown future climate conditions, from unknown future water demand scenarios and lack of knowledge about how society might respond to long-term droughts, from low-flow measurements with poorly understood errors, and from structural errors in hydrological models used to assess the impact of potential future rainfall deficiencies altered by climate change (Singh et al., 2014). Epistemic uncertainties in estimates of drought-related consequences and losses stem from the scarcity of data on and the difficult valuation of the impact and damage induced by water shortages.

\subsection{Uncertainty quantification in drought hazard estimation}

Drought hazard is widely assessed using indices, such as the standardized precipitation index (SPI) or Palmer drought severity index (PDSI). The most straightforward of these consider single environmental variables, such as precipitation (SPI) or groundwater level (Standardized Groundwater Index, Bloomfield and Marchant, 2013). In such cases, sources of uncertainty are restricted to the reliability of recorded observations, which may arise for instance from missing data or incomplete and short records (Hong et al., 2014; Hu et al., 2014). However, the information content of such indices can be low as rainfall or groundwater levels are not the sole drivers of drought impacts. By contrast, more complex indices such as PDSI and the crop moisture index provide a more applicable representation of drought, but with more sources of potential uncertainty due to multiple data sources, parameterizations, and model structures imposed by the indices. For instance, the Palmer drought severity index or the crop moisture index assume that land use and soil properties are uniform over large spatial scales, which makes it difficult to accurately identify the spatial extent affected by a drought (Narasimhan and Srinivasan, 2005). Parameter uncertainty in some drought indices is rarely considered when characterizing drought, yet it has been shown to play a significant role in the identification of major drought events and in the derivation of relevant drought statistics (Samaniego et al., 2013).

Under specific local conditions, shortage of rainfall can have an influence on water availability for human use at a regional scale within 4 months (Marsh et al., 2007). Long droughts can be difficult to characterize as multiple periods of drought can be interrupted by wet weather events, without sufficient rainfall arriving to restore water storage. Acknowledging this, long drought events such as the 18901910 drought in England and Wales and the Millennium drought in Australia can be pernicious, gradually depleting water stored in aquifers and reservoirs. Historically, drought indices and other water availability metrics such as deployable output (DO) in the UK have been presented without associated quantification of uncertainty. This is unfortunate, both in terms of the complexity of the calculation of such figures and because these terms are widely adopted by legal and regulatory systems. Recently, a risk-based approach has been proposed by Hall et al. (2012). Under this approach, probabilistic uncertainties are considered explicitly within the model and simulations are based on environmental time series, allowing metrics such as the probability of water shortages to be determined. This allows uncertainties to be examined simultaneously - conditional on the time series used to inform the model being representative of those driving the real system. As with other hazard areas, defining the probabilities required may also be subject to lack of knowledge.

Estimation of stream flow, and in particular low flows, is essential for hydrological drought analysis, thus the choice of methods to model and estimate low-flow characteristics can introduce epistemic uncertainties in drought risk assessment. Distributions fitted to low flows are susceptible to bias introduced by the fitting methodology and distribution choice (Ries and Friesz, 2000). Uncertainty is introduced in observations because many river gauging methodologies are especially poor at recording low flows (Barmah and Varley, 2012; Tomkins, 2014; Coxon et al., 2015). As gauging methods 
record proxy observations of flow, epistemic uncertainty in functional relationships (i.e. changes in channel cross section or vegetation affecting the correlation between stage and discharge) is likely to have a relatively greater effect on the absolute errors of low-flow observations (Tomkins, 2014; McMillan and Westerberg, 2015). While there is significant attention paid to information-rich events such as recession rates following flood events, the assumption that recession parameters determined in this way are optimal for determining the hydrology of extended low-flow series is not valid (Prudhomme et al., 2012, 2013). Hydrological models, which are routinely applied to model low-flow occurrence and to characterize hydrological drought duration and deficits in response to particular climatological conditions, also introduce epistemic uncertainty in drought risk assessments. For example, Duan and Mei (2014) have shown that hydrological model structural uncertainty induces large differences in drought simulation, while Hartmann et al. (2017) demonstrated that fluxes connecting surface and groundwater are often modelled with insufficient process realism in largescale hydrologic models, the scale where drought assessment is most relevant.

Drought risk can be characterized using metrics of drought duration and intensity (the deficit of water during a drought event), or the joint probability of a sequence of reduced flow events either in isolation or in combination with a water supply system model to assess future drought risk. Drought duration is indicative of drought severity rather than directly responsible for consequence in itself, as a long period of low flow is not necessarily worse than a short, sharp drought. Intensity can be considered a more robust metric of shortage as deviation from a threshold state can develop as a consequence of brief periods of extreme shortfall, longer mild shortfall or some combination of the two. Both these methods are sensitive to the identification of a threshold, which can be non-stationary due to environmental factors. Autocorrelation in drought series can be difficult to identify due to the requirement of capturing both the different temporal scales (daily, annual) and the continuous range of low flows, as correlation in Q99 events may be independent from correlation in Q95 events.

Epistemic uncertainties related to future climate conditions influence drought risk assessment for water resource planning purposes. A number of studies have investigated forward uncertainty analysis of the potential impacts of climate change on droughts (e.g. Wilby and Harris, 2006). Borgomeo et al. (2014) developed a risk-based method to incorporate epistemic uncertainties related to climate change in water resources planning and to assess drought and water shortage risk in water supply systems. This riskbased method incorporates climate change epistemic uncertainty by sampling the United Kingdom Climate Projections' (UKCP09) change factor distribution. Sampling different vectors of change factors allows for exploration of some degree of epistemic uncertainty in the future climate, within the range of the UKCP09 scenarios. Epistemic uncertainties arising from emissions scenarios and climate model choice has been addressed using a similar approach by Paton et al. (2013).

Although climate models may provide information about future drought risks, there are issues here about how far current climate models can reproduce the type of blocking high-pressure conditions that lead to significant droughts in Europe. Consequentially, the probabilities of multi-year droughts under future climates will almost certainly be poorly estimated. In this context, the historical periods of 1933-1934 and 1975-1976 in the UK are still used as extreme cases for water resource planning purposes. This is a form of precautionary approach that does not require any estimate of probability associated with that event, but one which involves some epistemic uncertainty about whether a more extreme event might occur in future. Worst-case scenario approaches have been applied by Kasprzyk et al. (2009) and Harou et al. (2010) to assess drought risk and evaluate drought management strategies in water resource supply systems undergoing change when human interventions modify vulnerability in a risk-based analysis, in addition to any climate changes (Mechler et al., 2010).

\section{Earthquakes}

\subsection{Earthquakes and key epistemic uncertainties}

Predicting earthquake occurrence is difficult, especially large seismic events in the very near future. Recently, the 2011 Tōhoku earthquake in Japan has highlighted that estimation of the maximum magnitude of mega-thrust subduction earthquakes involves significant epistemic ("deep") uncertainty related to segmentation of seismic sources and maximum magnitude (Stein et al., 2012; Kagan and Jackson, 2013), which can lead to the gross underestimation of earthquake scenarios. In a rather different scenario, during the 20102011 Christchurch sequences in New Zealand, the complex behaviour of interacting fault systems caused clustering of multiple major events in the Canterbury region that also resulted in major economic impact. Generally, earthquake hazards are influenced by the stochastic nature of earthquake occurrence and their size as well as by uncertainties in ground motions at sites of interest, which are contributed to by uncertainties in source, path, and site characteristics.

A standard approach for characterizing potential future earthquakes is probabilistic seismic hazard analysis (PSHA; Cornell, 1968; McGuire, 2001, 2004). PSHA was an engineering endeavour to develop a set of seismic hazard estimates for aiding the revision and implementation of seismic design in national building codes, using numerical methods that reflected limitations in the computing power of the time. In PSHA, key uncertainties related to earthquake occurrence in time and space, earthquake magnitude, and ground mo- 
tion prediction are all captured. However, in the past, major earthquakes have often been surprises, indicating that our knowledge is not perfect and that some of the probabilistic assumptions were inappropriate. We learn new things from these events and are sometimes required to revise theories and pursue alternative frameworks in the light of new observations (e.g. Mulargia et al., 2017).

\subsection{Uncertainty quantification in earthquake hazard estimation}

PSHA takes into account numerous earthquake sources and scenarios and integrates their contributions probabilistically as if all variables considered are aleatory in nature. Outputs from PSHA are provided in various forms, such as sitespecific hazard curves for safety-critical facilities and a regional hazard contour map. The contour map shows expected ground motions (e.g. peak ground acceleration and spectral accelerations) across a wide area or region at a selected annual exceedance probability level (typically 1 in 500 to 1 in 10000).

Representations of uncertainties in PSHA. PSHA involves various types and sources of uncertainties, and thus it is crucial to adopt an adequate mathematical framework to handle uncertainties as probabilities for individual model components and their dependency (Woo, 2011). Physically, these uncertainties can be associated with earthquake occurrence processes in time and space, seismic wave propagation, and seismic effects on structures and socioeconomic systems. PSHA also allows the identification of critical hazard scenarios at different probability levels through seismic disaggregation (McGuire, 2004). This essentially closes the loop between probabilistic and deterministic seismic hazard approaches, which are complementary in nature (McGuire, 2001). The deterministic scenario approaches (e.g. Zuccolo et al., 2011) allow the use of more definitive models and data, but without attempting to associate a probability with a given scenario. For evaluating seismic risk impact to safety-critical facilities and infrastructure, both approaches should be implemented and should also be accompanied by rigorous sensitivity analysis.

Epistemic uncertainties arise both in the choice of structure for the component models and in the effective values of the parameters necessary. As with the other natural hazards, this means that when model predictions are compared to observational data the prediction errors can have a complex structure that may not be simply aleatory. In PSHA, representations of alternative hypotheses and assumptions for individual model components are often framed with a logic tree approach (Kulkarni et al., 1984), and the final estimates of seismic hazard parameters are obtained by integrating relevant uncertain model components and by weighting of alternative assumptions. A benefit of using a logic tree, despite its simplicity, is the transparency in characterizing epistemic uncertainties. In this regard, the logic tree approach is similar to the condition tree of analysis assumptions outlined by Beven and Alcock (2012). Nevertheless, major difficulties arise because not all models, which analysts wish to apply are based on consistent data or assumptions, and the probabilities of alternatives in the logic tree are often poorly known, unknown, or unknowable (Bommer, 2012; Stein and Stein, 2013).

Thus, in practice, given these epistemic sources of uncertainty, it is not a trivial task to assign weights to individual branches of the constructed logic tree and, often, resorting to expert elicitation is the only practical solution. For major industrial facilities (e.g. dams and nuclear power plants), the development of the logic tree is often carried out according to the Senior Seismic Hazard Analysis Committee (SSHAC) guidelines for using expert advice (Budnitz et al., 1997). In the face of epistemic uncertainties and a wide spread in experts' opinions, special care is essential to avoid the inflation of elicited uncertainties and parameter distributions (Aspinall and Cooke, 2013).

Two of the critical elements in PSHA, which are linked but are both subject to considerable epistemic uncertainties, are the estimation of long-term occurrence rates of large earthquakes and the evaluation of the maximum magnitude for use in a PSHA, for a given seismotectonic environment. On occasion, the upper bound of the maximum magnitude may not be constrained either physically or statistically (Kagan and Jackson, 2013). The difficulty simply stems from the fact that records of seismicity data are insufficient to derive such long-term occurrence rates reliably, solely from historical catalogues or instrumental databases. The quality, completeness, and reliability of an earthquake catalogue evolves over time, affected by the distribution of human settlements and the way in which major events in the historical record have been reported or recorded, by advances in measurement technology and, more recently, the wider geographical coverage of seismographic networks. This often results in inhomogeneous detection and monitoring capabilities of instrumental catalogues (Tiampo et al., 2007), which need to be accounted for in evaluating earthquake occurrence rates. In addition, new information from terrestrial and ocean geodesy (McCaffrey et al., 2013; Bürgmann and Chadwell, 2014) will help constrain seismic hazard estimates derived from PSHA.

Epistemic uncertainties in earthquake occurrence characterization. Estimating frequency of occurrence of events for an individual fault or fault system and their magnitudes is highly uncertain and depends strongly on assumptions (Murray and Segall, 2002). In particular, it is difficult to determine the continuity of fault segmentation (Shen et al., 2009). In such cases, different hypotheses regarding the rupture behaviour of the fault system may be represented by branches of a logic tree. Recent PSHA studies for potentially active but less well-instrumented seismically active regions (e.g. the East African Rift) have extended the modelling basis for regional seismicity beyond historical and instrumental earthquake catalogues by using information from mapped geological faults and geodetically determined rates of strain ac- 
cumulation (e.g. Hodge et al., 2015). It is noteworthy that while such PSHA assessments remain significantly uncertain, they may be better able to capture potential extreme (surprise) events. Rigorous sensitivity analysis should include testing alternative hypotheses and comparing the impacts of the adopted assumptions on regional seismic hazard assessments (see, for example, the flooding example by Savage et al., 2016). In this regard, a PSHA should be reviewed, even from a modern instrumental perspective, such that a better understanding of seismic hazard assessments and their uncertainties can be achieved (Woo and Aspinall, 2015).

It has become more established in recent years that the mean occurrence rates of earthquakes on many mature fault systems and in subduction zones (where multiple plates meet and interact) are non-Poissonian and quasi-periodic (in contrast with a homogeneous Poisson model in the classical formulation of PSHA), and thus the hazard and risk potential posed by specific faults or subduction zones may be regarded as time-dependent (Sykes and Menke, 2006). Both physics-driven occurrence models (Shimazaki and Nakata, 1980) and statistics-based renewal models (Cornell and Winterstein, 1988; Matthews et al., 2002) have been adopted in PSHA. A notable example of an active seismic region that is affected by a renewal earthquake process is the Cascadia subduction zone. A unique aspect of this subduction zone is that repeated occurrences of $M_{\mathrm{w}} 9$-class mega-thrust earthquakes - due to subduction plate motions - have been recognized from field evidence only relatively recently (Satake et al., 2003; Goldfinger et al., 2012). In other words, the occurrence and rupture processes of the Cascadia subduction zone involve major epistemic uncertainties, and yet detailed hazard and risk assessments are necessary from an earthquake disaster preparedness viewpoint. In the last decade, various seismic hazard and risk studies for possible risk mitigation have been carried out by adopting a wide range of timedependent models and possible rupture scenarios as a way of trying to account for sources of epistemic uncertainty (Goda and Hong, 2006; AIR Worldwide, 2013). This situation contrasts with the case for the 2011 Tōhoku earthquake, where the consideration of extreme events was not taken up in risk mitigation actions prior to this event, even though there were indications of the impacts of past major tsunami-inducing events in the region (Stein et al., 2012). In this case and that of the Cascadia zone, current knowledge and understanding of subduction events are likely to be further updated in the very near future by seafloor geodesy in particular and so the scientific assessment framework and tools for better quantifying the characteristics and patterns of such earthquakes should also evolve dynamically.

Characterizing seismicity for the purposes of PSHA is always challenging, even in areas with plentiful data, and even more so when it comes to estimating background or diffuse seismicity away from known active regions or in low seismicity areas. Conventionally, this has been tackled, following Cornell (1968), by developing an area source zone model, each component of which is associated with an annual occurrence rate (above a minimum magnitude) and a GutenbergRichter type magnitude distribution. However, because earthquakes are a manifestation of a geological process, epistemic uncertainties in relation to earthquake magnitude-occurrence rates - especially at high magnitudes - should not be derived solely from the statistical properties of recent monitoring datasets or even historical catalogue information, either of which is just a limited snapshot sample of the underlying process. The danger here is that the analyst, in considering how to characterize a seismicity model for PSHA, is seduced into deriving a model conditioned on the available data, rather than understanding the probative weight of that data given an infinitude of plausible causal process models: naively letting "the data speak for itself" in PSHA can easily be undermined by future events, as evinced by the Tōhoku earthquake. Thus epistemic uncertainty quantification of seismicity should be based on a wider assessment that integrates in other difficult aspects, using expert judgment - such as slip and strain or stress rates and geological and tectonic controls - in order to supplement the limitations of available data (Aspinall, 2013; Aspinall and Cooke, 2013). This precept applies equally, or should do, to other factors and parameters in a PSHA, e.g. maximum magnitude and focal depth distribution. The corollary to this, in practice, is that rigorous sensitivity testing of input parameters can provide a wider perspective for epistemic uncertainty in earthquake occurrence characterization.

Epistemic uncertainties in ground motion modelling. In modern practice, considerable effort has been invested in respect of ground motion prediction equations, which constitute another major source of uncertainties in PSHA. Empirically derived prediction models using observed strong motion records are inherently limited by the availability of such data. Even following the dramatic expansions of strong motion networks in active seismic regions (e.g. California and Japan), near-source strong motion data and strong motion data for very large earthquakes (with the notable exception of the 2011 Tōhoku earthquake) are still lacking. This reality forces us to update existing empirical ground motion models from time-to-time by incorporating newly available data or to use computational model simulations of strong motion (e.g. Skarlatoudis et al., 2015). Another important issue, related to ground motion modelling using observed records, is that the majority of the existing ground motion models have been developed based on the ergodic assumption (Anderson and Brune, 1999). The ergodic assumption in the context of ground motion modelling implies that the ground motions required at a specific location can be substituted by recorded ground motions at different locations. There may be limited physical validity for this assumption in reality and, at best, adopting it faute de mieux engenders exaggerated epistemic uncertainty in the site-specific case via regression scatter estimates. In practice, the consequences of adopting this working hypothesis are biased seismic hazard assessments (Atkin- 
son, 2006). New formulations of ground motion models have started to address some of these issues (e.g. Stafford, 2014) but require additional functional relationships and parameters that remain subject to epistemic uncertainties.

\section{Tsunamis}

\subsection{Tsunamis and key epistemic uncertainties}

Massive tsunamis triggered by large earthquakes pose major threats to modern society, generating fatalities, disrupting socioeconomic activities, and causing grave economic impact across the world. Forecasting tsunamigenic earthquakes is challenging for the same reasons discussed above for prediction of mega-thrust earthquakes. Major sources of epistemic uncertainties are related to earthquake rupture processes (e.g. source areas and size, asperity, and kinematic and dynamic rupture process) and inundation or run-up process (e.g. topographical effects, land surface friction, and flow dynamics in urban areas).

\subsection{Uncertainty quantification in tsunami hazard estimation}

As noted in the last section, estimating potential earthquake size is one of the most critical factors in predicting the impact of great tsunamis. Inappropriate application of seismological theories could result in gross underestimation of earthquake magnitude of mega-thrust subduction earthquakes (Kagan and Jackson, 2013). A large earthquake may also trigger a submarine landslide, which acts as secondary sources for tsunami generation (Tappin et al., 2014). To gain further insights into the earthquake rupture process, source inversions can be carried out to characterize the space-time evolution of tsunami-causing ruptures by matching key features of simulated data with observations. Although sophisticated mathematical frameworks for source inversion have been developed and implemented, derived earthquake rupture models vary significantly, depending on the methods and data used for inversion (Mai and Beroza, 2002; Lavallee et al., 2006).

Topographical features of near- and on-shore areas have major effects on tsunami waves and inundation or run-up. The spatial resolution and accuracy of bathymetry and digital elevation models (DEM) are important for representing local terrain features realistically. Typically, the frictional properties of terrain features are modelled by Manning's roughness coefficients. Different data resolutions will require different effective roughness coefficients, thus affecting tsunami inundation extents. The impacts of uncertainty in the DEM and roughness coefficients will depend on tsunami hazard parameters (Kaiser et al., 2011). For instance, the inundation depths are less sensitive to the data resolutions and characteristics, whereas the flow velocity and momentum, which are also important in evaluating the tsunami-induced forces on buildings (Koshimura et al., 2009), are more sensitive. This issue be- comes even more critical when tsunami inundation in dense urban areas is investigated, where buildings may be represented as (impermeable) elevation data. The simulated flow velocities in urban streets can be very high.

It is rare that uncertainties of the DEM data and roughness coefficients are taken into account in conducting tsunami simulations but adopting the same modelling philosophy as the PSHA of the last section, probabilistic tsunami hazard analysis (PTHA) has been developed and applied to some major tsunami-prone regions (e.g. Annaka et al., 2007; Thio et al., 2007; Horspool et al., 2014). The main focus and advantage of PTHA are to integrate potential tsunami hazards from various sources (both near-field and far-field) in a probabilistic framework. Epistemic uncertainties are represented in PTHA through a logic-tree approach by assigning weights to alternatives for different model components, noting that the criticisms of PSHA (e.g. Mulargia et al., 2017) are also applicable to PTHA. The final output is a tsunami hazard curve and probabilistic tsunami inundation maps of inundation depth and other relevant parameters. A major difference between PTHA and PSHA is that differential equations of tsunami wave propagation and run-up (typically shallow water equations) are evaluated directly, whereas in PSHA, seismic wave propagation (as well as earthquake rupture and site response) is approximated using empirical ground motion models. The direct simulation of tsunami waves reduces the uncertainties associated with tsunami hazard assessment and provides additional information on the tsunami wave timehistory and arrival time.

However, PTHA can be computationally demanding. To achieve computational efficiency, PTHA is often formulated based on linear superposition of tsunami waves (i.e. Green's functions) for simplified earthquake sources and is carried out only for near-shore locations (e.g. at $30 \mathrm{~m}$ depth). The inundation and run-up processes are often modelled by applying amplification factors (e.g. Løvholt et al., 2014). To improve the tsunami hazard prediction and quantify the effects of epistemic uncertainties, it is desirable to integrate the stochastic source modelling approach (which carries out fully nonlinear inundation simulation of tsunami waves; Goda et al., 2014) into the PTHA methodology. De Risi and Goda (2016) have developed probabilistic earthquaketsunami multi-hazard analysis based on the stochastic source modelling approach. Such an extended PTHA can reflect the variability of source characteristics for specific scenarios as well as numerous tsunami sources in developing tsunami hazard curves and maps. 


\section{Volcanic eruptions and ash clouds}

\subsection{Volcanic eruptions, ash clouds, and key epistemic uncertainties}

The 2010 eruption of Eyjafjallajökull in Iceland provided a dramatic demonstration of the potential for volcanic ash clouds to become a natural hazard. Due to the synoptic weather at the time of the eruption, the ash cloud caused enormous disruption to air travel across Europe and the Atlantic with some 10 million air travellers being affected. The total global cost in GDP over the entire eruption was estimated at USD 5 billion (Mazzocchi et al., 2010). As then there has been considerable effort expended in the monitoring and prediction of volcanic ash clouds. Ash clouds can also be a problem in many other parts of the world, for example as a result of the continuing eruption of Mount Sinabung in Indonesia and the recent 2015 eruption of the Calbuco volcano in Chile. Globally, a network of nine Volcanic Ash Advisory Centres (VAACs) provides warning services based on monitoring and modelling. Major epistemic uncertainties include the magnitude of the source term or mass emission rate, near field processes affecting ash size distribution and deposition, and the interaction of the eruption and synoptic weather patterns in affecting the far-field ash dispersion.

\subsection{Uncertainty quantification in volcanic and ash cloud hazard estimation}

Infrared satellite observations are perhaps the most important tools for monitoring ash but are not without their problems. Ash detection is complicated by a number of factors. The brightness temperature difference (BTD; the difference between brightness temperatures at two infrared channels) used as the basis for infrared ash detection can be affected by false positives and false negatives due to atmospheric conditions (Simpson et al., 2000; Mackie and Watson, 2015), land surface type and temperature, presence of other aerosols (Prata, 1989; Prata et al., 2001; Pavolonis et al., 2006; Lee et al., 2014) and water or ice (Rose et al., 1995), in addition to particle size (e.g. Millington et al., 2012) and ash cloud opacity (Rose et al., 2001) (see Fig. 3).

Many assumptions are made about the physical properties of ash in order to make estimates of other physical properties such as ash column loading, ash cloud height and effective radius. For example, in the Met Office 1D-Variational (1DVar) volcanic ash retrieval scheme (Francis et al., 2012) it is assumed that ash particles are spherical to simplify the absorption and scattering calculations, the particle size distribution (PSD) is assumed to be log-normal in shape, and the geometric standard deviation of the distribution is selected from a number of possible values. However, this value can have a significant effect on retrieved ash column loading, e.g. Western et al. (2015). Ash composition, and hence, refractive index data must also be assumed, adding considerable

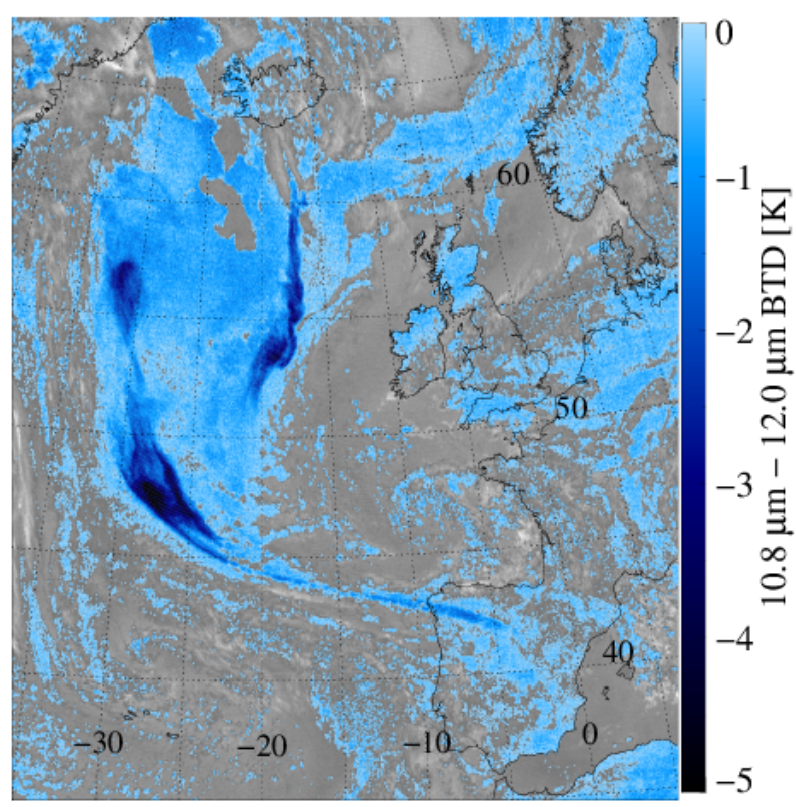

Figure 3. Meteosat Second Generation Spinning Enhanced Visible and InfraRed Imager (SEVIRI) brightness temperature difference image (brightness temperature at the $10.8 \mu \mathrm{m}$ channel minus the brightness temperature at the $12 \mu \mathrm{m}$ channel) indicating the extent of the Eyjafjallajökull ash cloud at 03:00 UTC 8 May 2010. The negative values of BTD (indicating ash) are shown in blue and the scale in kelvin is given on the legend. The positive BTD is plotted in grey. A likely false negative ash signal can be seen south of Iceland where the ash plume appears to be obscured, possibly by meteorological cloud, due to the high ash concentration causing opaqueness, a large fraction of large particles or the presence of water in the plume. A negative BTD signal can be seen over North Africa and southeastern Spain, possibly due to a night-time clear arid land surface. Raw data supplied by EUMETSAT.

uncertainty (Mackie et al., 2014). There are limited ash refractive index data available, and this choice can also have a significant effect on derived ash properties (e.g. Francis et al., 2012). The PSD geometric standard deviation and refractive index data set are varied within the 1D-Var algorithm and the solution with the lowest cost is generally used; the solution cost of the 1D-Var scheme can be used as an uncertainty measure, with high costs indicating high uncertainty (Stevenson et al., 2015).

Within volcanic ash retrieval schemes, other sources of uncertainty are introduced, for example in the simulation of satellite imagery using a radiative transfer model, in the meteorological data used within the model, interpolation of that data and so on. Only some of these uncertainties are very generally accounted for the in $1 \mathrm{D}$-Var algorithm. Other types of observations (e.g. hyperspectral satellite observations, satellite, aircraft or ground-based lidar) can add useful information on ash layer depth, particle size distribution and the height of the ash cloud. Combining these observations 
with infrared satellite observations can help reduce epistemic uncertainty in the derived observational data. However, they can often be of much lower temporal or spatial resolution and carry their own assumptions and uncertainties.

However, modelling of the hazard using volcanic ash dispersion models is a problem of forecasting. At the UK Met Office the Numerical Atmospheric-dispersion Modelling Environment (NAME) model (Jones et al., 2007) is used in both simulation and forecasting of ash to inform the London VAAC, which covers eruptions in Iceland and the impacts on northwestern Europe. As with all models, NAME is a simplified representation of the problem, and does not include some of the complex physical processes that control the behaviour of an ash field close to the source of the eruption, notably fall out of very large grains and particle aggregation. Near-field processes are still the subject of current research (e.g. Taddeucci et al., 2011). Currently, the effects of gravity currents (Bursik et al., 1992a; Sparks, 1986) are also not included in most atmospheric dispersion models. These near-source processes are likely to dominate ash dispersion and transport close to the source, and for large eruptions they could dominate for hundreds of kilometres (Bursik et al., 1992a, 1992b; Sparks et al., 1997), but far from the source are unlikely to affect downwind ash clouds for weak eruptions (Costa et al., 2013; Devenish et al., 2012b).

In NAME an effective source term is used as a boundary condition for forecasting the far-field transport and deposition of ash. This includes assumptions about the PSD of the ash. Plume behaviour can vary significantly over time and information derived from deposited ash, often after an event, does not necessarily give a good indication of the PSD within the distal ash cloud (Bonadonna and Houghton, 2005). Operationally, a default source term PSD has been used by the London VAAC, based on empirical measurements from Hobbs et al. (1991), which aims to represent the fine ash that survives near-source fall-out (Webster et al., 2012). This component may be of the order of $0.05-10 \%$ of the total erupted mass (Mastin et al., 2009) and consequently constitutes a significant source of uncertainty. Mass emission rate (MER) and particle density are also required and are also very difficult to determine experimentally. MER is often represented as a simple empirical power law as a function of plume height with fixed parameters (e.g. Mastin et al., 2009), while in a study of the Eyjafjallajökull eruption, Webster et al. (2012) used a fixed ash density value of $2300 \mathrm{~kg} \mathrm{~m}^{-3}$. It is thought that the empirical function for MER may be biased towards observed data from larger eruptions (Woodhouse et al., 2013). Plume height measurements used to determine MER (e.g. radar) are subject to uncertainties (Arason et al., 2011; Folch et al., 2012), and plumes from weak eruptions such as Eyjafjallajökull can become distorted by local winds, increasing plume height measurement uncertainty and thus affecting the MER calculation (Webster et al., 2012). Meteorological data can also introduce uncertainty to dispersion forecasts, and can lead to cumulative transport errors (Dacre et al., 2016). All of these factors represent primary epistemic uncertainties in the application of such models. Even a cursory treatment of those uncertainties results in a significant predictive uncertainty (Devenish et al., 2012a). The treatment of uncertainties in complex models such as NAME can be difficult due to computational constraints. Emulation is one strategy to overcome this limitation as demonstrated in the study by Harvey et al. (2018) using the NAME model. Their emulator allowed for the estimation of prediction uncertainties and for identifying key uncertain parameters.

One way of constraining such uncertainty during simulation (rather than forecasting) is to use inversion modelling to learn more about model eruption source parameters (ESPs) (and possibly dispersion processes such as sedimentation, wet and dry deposition and atmospheric turbulence parameters), based on the available observations and prior information (e.g. Kristiansen et al., 2012; Moxnes et al., 2014; Pelley et al., 2015; Stohl et al., 2011). In this way, Kristiansen et al. (2012) estimated optimal volcanic ash source terms for the Eyjafjallajökull eruption using an inversion algorithm with satellite-retrieved ash column loadings, a number of emission scenarios and two atmospheric dispersion models. The inversion-estimated source terms were applied within the models a posteriori to perform long-range forecasts and results were validated using lidar and in situ PSD measurements from research flights. Uncertainties in the a priori emission estimates, model and observations were taken into account within the inversion algorithm, allowing the result to deviate from the a priori emission assumptions and the observations according to the errors.

Wilkins et al. $(2014,2016)$ used data insertion to initialize NAME using measurement-derived data. Instead of releasing ash with a defined release rate from the volcano vent, it was released several times from "snapshots" of downwind ash clouds defined using retrieved data from infrared satellite imagery, in situ and other remotely sensed data. While this method does not explicitly deal with uncertainties in the model or observations, it could potentially be used to bypass basic epistemic uncertainties in the ESPs, for instance where the location of the volcano is unknown. However, the method does require estimations of ash layer thickness, vertical distribution and PSD. An inversion modelling based Bayesian method was adopted by Denlinger et al. (2012) to propagate uncertainty in ESPs within an atmospheric dispersion model and estimate forecast uncertainty. A genetic algorithm variational method was applied by Schmehl et al. (2011) to elucidate wind direction, wind speed and mass emission rate to be used for forward assimilation in a dispersion model. By sampling the source term parameter ranges iteratively, the results could be used to constrain uncertainty in ESPs and/or meteorological fields. 


\subsection{Uncertainty quantification in real-time volcanic and ash cloud hazard warning systems}

When such models are used for forecasting it is possible to compensate for epistemic uncertainties, at least in part, by the real-time assimilation of information about the ash cloud derived from remote sensing and other direct sources such as experimental flights. Data assimilation will then implicitly compensate for some of the epistemic uncertainty associated with the model. However, the propagation of complex uncertainties in computationally expensive atmospheric-dispersion models is a time consuming and difficult problem to quantify. The characterization of volcanic ash forecast uncertainties in an operational timescale thus remains a challenging task.

\section{Pyroclastic density currents}

\subsection{Pyroclastic density currents and key epistemic uncertainties}

Rapidly moving flows of hot, fragmented gas-rich magmatic products in pyroclastic density currents (PDC; also known as nuées ardentes or pyroclastic flows and surges) are the biggest threat to human life during explosive volcanic eruptions. The $79 \mathrm{CE}$ eruption of Vesuvius and the remains found at Herculaneum and Pompeii represent a classic historic example of the disastrous impacts of PDCs, and any repeat example of this volcano in the future, even on a smaller, less intense scale, could have massive consequences for the heavily populated surrounding area. Hazard and risk assessments for this situation, undertaken in the last twenty years for the National Emergency Plan (DPC, 1995, 2001), were mostly based on the characterization of a single "maximum expected event" (MEE). Such an event largely corresponds in the expected intensity of effects to the hazardous phenomena that occurred during the last sub-Plinian eruption of Vesuvius, in 1631CE. However, that definition was not based on a fully quantitative analysis of the whole system and potential ranges of eruptive activity, and no probabilistic estimates were provided for the occurrence of the hazard events being considered. Significant knowledge gaps still exist regarding the factors that control their initial formation, their movement across terrain and the ways they injure and kill people, and damage structures.

\subsection{Uncertainty quantification in pyroclastic density currents hazard estimation}

In an extensive study of the Vesuvius region, Neri et al. (2008) discuss how a structured expert elicitation procedure was implemented to complement more traditional data analysis and interpretative approaches, and to add a formalized approach to the generic incorporation of epistemic uncertainty in the assessment by way of the Event Tree formu- lation. A Vesuvius "Event Tree" was created to summarize the relative likelihoods of the genesis and style of eruption, development and nature of volcanic hazards, and the probabilities of occurrence of different volcanic risks in the next eruption crisis. To achieve a complete parameterization for this approach, hazard and risk models were needed. These were quantified with uncertainty distributions for pyroclastic flow run-out distances, peak pressures, and temperatures rather than use of "best-estimates".

In Neri et al. (2008), the focus lay on addressing the issues of epistemic uncertainty in relation to the physical characterization of PDC potential during a sub-Plinian column collapse eruption, and how the topography of the volcano influences hazard and risk mapping results. A transient 3D parallel code PDAC was used to simulate the dynamics of the collapse of the volcanic column and the propagation of the associated PDCs (Esposti Ongaro et al., 2007; Neri et al., 2003). However, the full ranges of plausible volcanic and other physical input parameter variations are not amenable to comprehensive exploration in a restricted number of scenario runs, which are limited by computing power and cost. Under these circumstances, the few PDAC runs that were possible were used as indicative reference simulations, with expert elicitations used to derive rational, quantitative statements about the most appropriate values to use for variables of interest and, more importantly, to give expression to the scientific uncertainty that attaches to the outcomes of such model runs. For instance, distributional expressions for uncertainties on pyroclastic flow run-out distances, peak pressures, and temperatures were obtained by elicitation, after detailed consideration of the few simulation model results that were achievable, and of field evidences, old and new.

This information was subsequently used to subdivide the Vesuvius area into different sectors (Fig. 4). Sector A includes the area "not protected" by Mt Somma, and Sector $\mathrm{B}$, the area which is "protected" - representing a first-order source of epistemic uncertainty in respect of the extent to which the presence of the Mt Somma topography could determine which areas could be invaded by flows or modify properties of the flows that might affect the two sectors. While overall predictive uncertainties were quite large, the elicited probabilities of invasion of the different sub-sectors of Sector A are each very similar, and apparently only weakly affected by the preferential propagation directions shown by some of the 3-D simulations (Esposti Ongaro et al., 2008) or by reconstructions of past sub-Plinian events (Rosi et al., 1993; Cioni et al., 2008).

The large epistemic uncertainties regarding the directional controls on PDC probabilities and likely run-outs influence the expected values of the main physical variables that can be associated with a PDC scenario, e.g. peak dynamic pressure and peak flow temperature. The fact that the Vesuvius study also resulted in large credible intervals associated with these parameter estimates, as well as with the PDC run-outs, clearly reflects expert perceptions of the significant degree 
(a)

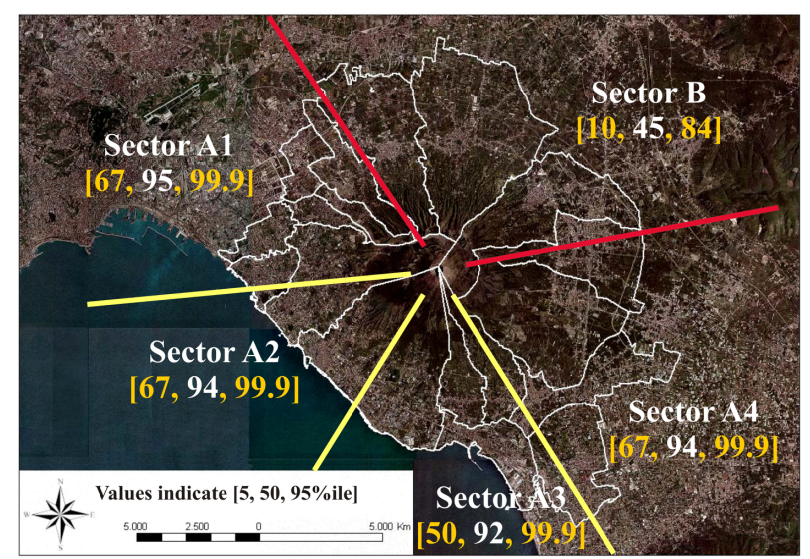

(b)

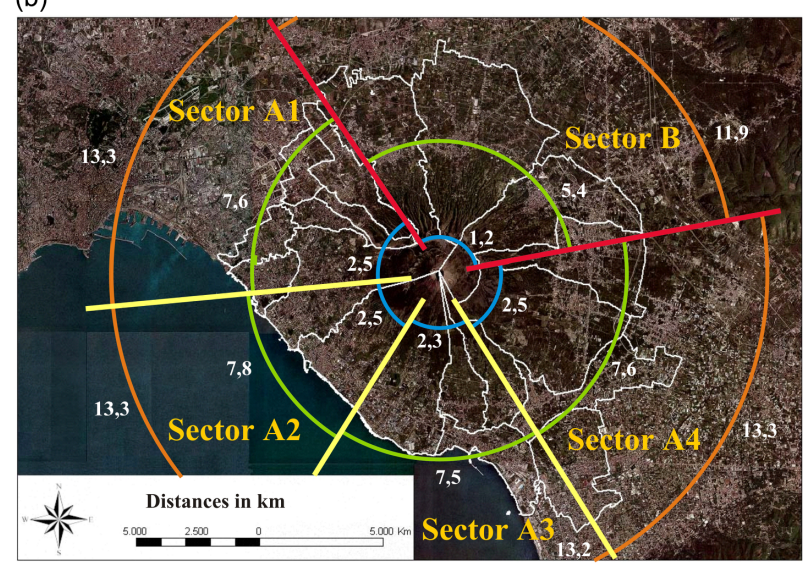

Figure 4. (a) Broad segmentation of area around Vesuvius recognizing the first-order effect of Mt Somma topography in determining areas that might be invaded by pyroclastic density current flows (PDC) as the result of a sub-Plinian I eruption. The bracketed values in each sector show elicited modal probabilities that a PDC will affect that sector (expressed in percentage terms) together with the corresponding credible intervals, in quantile form [5th, 50th, 95th percentiles]. (b) Elicited estimates of maximum run-out distances (in $\mathrm{km}$ ) for PDCs occurring during a sub-Plinian I eruption, by sector. Inner arcs (blue) are $95 \%$ confidence levels for exceeding distance shown (e.g. $2.5 \mathrm{~km}$ for Sector A1), central arcs (green) are expected (50th percentile) values, and outer arcs (orange) are the run-out distances assessed has having only a $5 \%$ chance of being exceeded. (from Neri et al., 2008, with permission).

to which epistemic uncertainties must affect current attempts to forecast the complex hazard processes being considered. One conclusion is that more field and more numerical work is needed in order to further constrain the areas likely to be affected by future PDCs at Vesuvius.

\section{Windstorms}

\subsection{Windstorms and key epistemic uncertainties}

Weather hazards are a major source of societal risk causing death, destruction to infrastructure, and disruption to transport and business. Global insured losses due to windstorms, currently estimated to cost USD 2.7 billion annually (Podlaha et al., 2017), are expected to rise dramatically due to climate-change-related trends in weather extremes, increasing exposure in developing countries, and increasing world population. Extratropical cyclones (also known as windstorms) are major contributors to this impact, e.g. insured losses in Europe of USD 9 billion for windstorm Daria (25 January 1990). Furthermore, windstorms often arrive in close succession, which enhances the risk of large aggregate losses, e.g. the winter 2013/14 cluster of European windstorms Christian, Xavier, Dirk, and Tini caused insured losses of USD 1.38, 0.96, 0.47 and 0.36 billion totalling USD 3.3 billion (source: https://www.perils.org/, last access: October 2018). Epistemic uncertainties in the estimation of windstorm risk stem largely from the (poorly supported) choices that have to be made during hazard and impact estimation.

\subsection{Uncertainty quantification in windstorm hazard estimation}

Windstorm loss distributions are inferred from historical weather measurement data (mainly available since 1950) and also increasingly from storm data simulated ab initio from numerical weather and climate prediction models (Schwierz et al., 2010; Pinto et al., 2010; Della-Marta et al., 2010; Renggli et al., 2011; Karremann et al., 2014). The loss distributions are estimated by Monte Carlo simulation using ad hoc combinations of various statistical, dynamical and engineering type models: statistical models for estimating trends and correcting inhomogeneities in the historical data (Barredo, 2010), either low-order parametric stochastic models (the traditional basis of many catastrophe models), or more recently, numerical weather and climate models for simulating large sets of artificial hazard events, statistical models for adjusting biases in numerical model output, and stochastic models for simulating losses from the artificial windstorm events (e.g. compound Poisson event loss table models).

As many choices are required to develop these models, there are many sources of epistemic uncertainty. The following is a list of just a few of the major uncertainties in each type of model.

- Stochastic hazard and loss models often use highly idealized non-physical description of complex storm processes (e.g. polynomial representation of storm tracks). There is the possibility of over-fitting to the data available from relatively short historical periods. There 
are often overly restrictive assumptions in simulating losses, e.g. homogeneity in time, independence of events, independence of frequency and severity.

- Statistical models require distributional assumptions, e.g. extreme value models (Brodin and Rootzén, 2009; Della-Marta et al., 2009), assumptions about modeldependence of simulated storms (Sansom et al., 2013), and assumptions about dependency in space-time and between events (Bonazzi et al., 2012; Economou et al., 2014).

- Numerical weather and climate models show biases in storm properties that have resisted model improvements over the past 40 years, e.g. zonal storm tracks over Western Europe (Zappa et al., 2013), poor representation of small horizontal scale processes even at very high resolution, e.g. wind gusts (Ólafsson and Ágústsson, 2007), missing processes, e.g. sting jets caused by mesoscale features such as stratospheric intrusions (Catto et al., 2010) and non-adiabatic forcing of storms by anomalous oceanic conditions (Ludwig et al., 2014).

- Finally, there is also a major overarching source of epistemic uncertainty in how these different model components should be coupled together. At present there is no accepted theory for how one should and should not do this.

Clustering of windstorms provides a good example of an epistemic uncertainty that has recently received much attention and thereby led to model developments. Analysis of historical reanalysis data revealed that windstorm modulation by large-scale climate modes leads to more clustering over Europe than one can expect by chance, i.e. from a homogeneous Poisson process (Mailier et al., 2006). Furthermore, clustering was also found to increase for more extreme wind speeds (Vitolo et al., 2009), in contradiction to the assumption often made by actuaries suitable for identically distributed variables. This research raised much awareness about clustering in the natural catastrophe insurance industry that has led to major developments in windstorm catastrophe models (Khare et al., 2015). The findings are also stimulating new research into mechanisms for clustering of extreme storms (e.g. Rossby wave breaking; Pinto et al., 2014).

\section{Co-emergent and cascading hazards}

The earlier discussion has mostly been concerned with the characteristics of individual hazards but it is clear that an assessment of risk often needs to allow for the joint occurrences of cascading multiple hazards, either for hazards of different types affecting a single location, or the joint occurrence of a hazard at multiple locations simultaneously (e.g. Lamb et al., 2010; Gill and Malamud, 2014; Keef et al., 2013; De Risi and Goda, 2016; Goda et al., 2017). Both will affect the assessment of the joint risk. In some cases the joint risk may be causative, including the dependence of numerous aftershocks triggered by a main shock (Yeo and Cornell, 2009); tsunamis initiated by ocean floor earthquakes and landslides (Tappin et al., 2014; Goda et al., 2016); the landslide and avalanches that result directly from earthquakes; and the potential for landslide as well as flood impacts on dam safety (an epistemic uncertainty that is usually neglected but which has caused past dam overtopping). In other cases, independent occurrences might contribute to an increased risk, such as the joint occurrences of fluvial floods, high tides, and atmospheric surge on the risk of estuarine and coastal flooding. Assessing the joint frequency of such events has been receiving increasing attention (e.g. Svensson and Jones, 2004). In particular, the covariation of different causes of the hazard, and joint occurrences across multiple locations has been investigated using flexible functional relationships based on overlap likelihood relationships (Gill and Malamud, 2014) and copulas (e.g. Keef et al., 2013). An interesting application of the latter was used to produce the probabilistic flood map of Fig. 2 in Sect. 2.2, which is affected by the joint occurrences of high flows both in the mainstream river and two major tributaries entering from the south (Neal et al., 2013).

\section{Uncertainty quantification related to the consequences of natural hazards}

Alongside uncertainties related to the characterization and propagation of the hazard itself (e.g. the footprint and magnitude of an earthquake), risk assessments also entail epistemic uncertainties arising from the uncertain consequences and damage of the hazard (i.e. the loss part of the risk assessment). Key components of such assessments are (Tesfamariam and Goda, 2013) exposure (e.g. spatial locations of populations and assets), vulnerability (e.g. characteristics of buildings and infrastructure), and loss (e.g. characteristics of assets and loss generation mechanisms). All these involve significant uncertainties. In the risk equation (i.e. convolution of hazard, exposure, vulnerability, and loss), these uncertainties are propagated and integrated. Uncertainties in exposure and loss are attributed to a lack of information, incomplete knowledge, as well as simplification adopted in the models, and thus are largely epistemic.

The consequences of hazards are often difficult to quantify and there is still little research available linking the characteristics of the hazard (e.g. drought duration and severity) to the related consequences (e.g. Jenkins, 2013). For past events there might be some epistemic uncertainty about the damages associated with the event, but there is often considerable uncertainty about what is actually at risk, i.e. the exposure (e.g. Chatterton et al., 2014). Damages that are claimed against insurance are generally well known (but subject to commercial confidentiality restrictions and not readily available in other 
than very general summary form), but not all damages are insured and not all are easily expressed in monetary terms (such as damage to habitats, cultural heritage, and loss of life). Indirect damages to businesses and individuals (e.g. as a result of infrastructure failures, health and psychological impacts) can also be difficult to assess. More geographically explicit damage relationships are needed for hazards such as droughts (Bachmair et al., 2015; Blauhut et al., 2015) or tsunamis (Goda and Song, 2016), which cover potentially large and heterogeneous areas. Potential sources of damage are even more difficult to estimate for future events, as a result of epistemic uncertainties (e.g. about policy changes in flood risk management, planning decisions for flood plain developments, changes in availability of insurance cover). Different chosen loss models might result in quite different estimates of the consequences of an event (e.g. Jongman et al., 2012; Chandler et al., 2014), to the extent that estimates of risk might generate significant controversy as a result of the epistemic uncertainties inherent in the assessment processes (e.g. Penning-Rowsell, 2015).

Epistemic uncertainties in the risk assessment of natural hazard consequences also arise from the interactions of the hazard with human actions. Consider the example of droughts. Because of their temporal and spatial extent, droughts are more prone to mitigation or exacerbation by socio-economic drivers than some other natural hazards. Those responding to or managing water resources during drought will make use of nearby water resources or stored water, thus actively intervening to influence the development and consequences of the event (Van Loon et al., 2016a). For instance, epistemic uncertainties arise from incomplete knowledge of how demand responds during times of drought to both environmental conditions (weather) and management actions (i.e. water use restrictions, price increases) (Kenney et al., 2008). Although hot and dry weather may increase demand in the short-term, it is not clear which climatic variables are best suited to explain water consumption patterns (Kenney et al., 2008). Over larger spatial and temporal scales, changes in water demand are difficult to project and add a level of epistemic uncertainty to any water resources planning decision. Water managers often rely on extrapolation processes (Jorgensen et al., 2009; House-Peters and Chang, 2011), yet this process has not been entirely successful, with the UK's largest reservoir at Kielder built to meet projections which did not foresee the decline in heavy industry in the North of England (Walker, 2012), a clear case of the impact of epistemic uncertainty about future boundary conditions but which, opportunely, has served to mitigate the effects of drought in the area. This type of uncertainty, combined with data gaps, makes the modelling tools available largely inadequate to predict drought impacts. Severe limitations exist in predicting the impacts of feedbacks and modifications to drought events due to human actions, calling for a new framework for drought risk assessment that includes the human role in mitigating (or enhancing) the consequences of drought (Van Loon et al., 2016b).

\section{Generalizations across hazard areas}

In reviewing the way in which epistemic uncertainties are handled in each of these natural hazard areas, certain commonalities are apparent. Most notable is the tendency for treating all sources of uncertainty as aleatory variables, for both the hazard and the consequences or impacts that make up the risk equation. In most hazard areas, probabilistic methods are replacing older deterministic probable maximum event methods. The probabilistic approach is attractive in that the power of statistical theory, including the use of judgement-based probabilities in a Bayesian framework, can be utilized. However, when used to represent epistemic uncertainties such an approach will be subject to the following limitations:

- not allowing for the incompleteness of probability assessments (including the probabilities associated with the branches of logic trees);

- the potential of over-fitting to limited historical records in estimating the frequencies of extreme events of unknown (and potentially non-stationary) distributional form; and

- the limitations of expert elicitation of prior probability and scenario information.

This suggests that an extension to a more explicit recognition of epistemic uncertainties might be necessary in future but might require the development of new methodologies that go beyond classic risk-based decision making, which is based on assuming that all sources of uncertainty can be treated in terms of aleatory variability. This will particularly be the case for what Day and Fearnley (2015) define as permanent mitigation strategies. Both responsive and anticipatory mitigation would benefit from the availability of more and better observations, though as noted in a number of the sections above, such observations may also be associated with epistemic uncertainties.

\section{Conclusions}

This paper has reviewed examples of how uncertainties in general, and epistemic uncertainties in particular have been handled in assessments of risk associated with different natural hazards. In most cases, epistemic uncertainties are not considered explicitly, but are still treated as if they can be considered as aleatory variables of specified distributional form. This can often lead to an underestimation of the uncertainty in the risk assessment and might lead to a lack of robustness of decision and to future surprise. It is therefore both 
possible and desirable to extend the analysis to explicitly include different scenarios of epistemic uncertainty. The analysis of different natural hazard areas presented above makes it clear that there are different degrees of appreciation for and approaches to dealing with epistemic uncertainty. We hope that making this comparison will enable researchers in different areas to learn about structured approaches that are being used elsewhere, particularly in dealing with uncertainties that are less amenable to being treated probabilistically.

Where observational data are available that can be used to constrain the prediction uncertainties in an application, then care should be taken in the form of model evaluation. Treating a residual series as a simple aleatory variable can be used to define a formal statistical likelihood function, but if the uncertainties are dominated by epistemic sources the result may be overconfidence in model selection and over-constraint of the predictive uncertainty. In the particular case of real-time forecasting, data assimilation can be used to adaptively compensate for unknown uncertainties in improving forecasts and constraining forecast uncertainties over the lead times of interest, at least where the data and models can be processed within the timescale of the system response or at a temporal resolution useful to decision makers.

The variety of assumptions and approaches being used in different hazard application areas reinforce the discussion that follows in Beven et al. (2018) about the importance of a framework for structured analysis and communication of the assumptions and the meaning of an uncertainty analysis, particular to the decision makers and other users. There is no single way of assessing the impacts of epistemic uncertainties on risk (for good epistemic reasons), but in encouraging good practice we can at least demand clarity in the assumptions that are made, with the possibility that this then might lead to some consideration and maybe even testing of alternative assumptions and a consequent reduction in the potential for future surprise.

Author contributions. All authors contributed to the preparation of this paper by either drafting or editing the individual sections.

Competing interests. The authors declare that they have no conflict of interest.

Acknowledgements. This work is a contribution to the CREDIBLE consortium funded by the UK Natural Environment Research Council (grant NE/J017299/1). Jeff Neal and Dave Leedal are thanked for their work in producing Fig. 2.

Edited by: Richard Chandler

Reviewed by: Richard Chandler and two anonymous referees

\section{References}

AIR Worldwide: Study of impact and the insurance and economic cost of a major earthquake in British Columbia and Ontario/Québec, Insurance Bureau of Canada, Toronto, Canada, 345 p., 2013.

Aleotti, P.: A warning system for rainfall-induced shallow failures, Eng. Geol., 73, 247-265, https://doi.org/10.1016/j.enggeo.2004.01.007, 2004.

Alfieri, L., Smith, P. J., Thielen-del, Pozo, J., and Beven, K. J.: A staggered approach to flash flood forecasting - case study in the Cevennes Region, Adv. Geosci., 29, 13-20, 2011.

Almeida, S., Holcombe, E. A., Pianosi, F., and Wagener, T.: Dealing with deep uncertainties in landslide modelling for disaster risk reduction under climate change, Nat. Hazards Earth Syst. Sci., 17, 225-241, https://doi.org/10.5194/nhess-17-225-2017, 2017.

Alonso, E. E., Gens, A., and Delahaye, C. H.: Influence of rainfall on the deformation and stability of a slope in overconsolidated clays: a case study, Hydrogeol. J., 11, 174-192, https://doi.org/10.1007/s10040-002-0245-1, 2003.

Anderson, J. G. and Brune, J. N.: Probabilistic seismic hazard analysis without the ergodic assumption, Seismol. Res. Lett., 70, 1928, 1999.

Annaka, T., Satake, K., Sakakiyama, T., Yanagisawa, K., and Shuto, N.: Logic-tree approach for probabilistic tsunami hazard analysis and its applications to the Japanese coasts, Pure Appl. Geophys., 164, 577-592, 2007.

Arason, P., Petersen, G. N., and Bjornsson, H.: Observations of the altitude of the volcanic plume during the eruption of Eyjafjallajökull, April-May 2010, Earth Syst. Sci. Data, 3, 9-17, https://doi.org/10.5194/essd-3-9-2011, 2011.

Aronica, G., Hankin, B. G., and Beven, K. J.: Uncertainty and equifinality in calibrating distributed roughness coefficients in a flood propagation model with limited data, Adv. Water Resour., 22, 349-365, 1998.

Aspinall, W. P.: Scientific uncertainties - a perspective from probabilistic seismic hazard assessments for low seismicity areas, in: Risk and Uncertainty Assessment in Natural Hazards, edited by: Rougier, J. C., Sparks, R. S. J., and Hill,, L., Cambridge University Press, Chapter 8, 234-274, 2013.

Aspinall, W. P. and Cooke, R. M.: Expert elicitation and judgement, in: Risk and Uncertainty Assessment in Natural Hazards, edited by: Rougier, J. C., Sparks, R. S. J., and Hill, L., Cambridge University Press, Chapter 4, 64-99, 2013.

Atkinson, G. M.: Single-station sigma, B. Seismol. Soc. Am., 96, 446-455, 2006.

Bachmair, S., Kohn, I., and Stahl, K.: Exploring the link between drought indicators and impacts, Nat. Hazards Earth Syst. Sci., 15 , 1381-1397, https://doi.org/10.5194/nhess-15-1381-2015, 2015.

Barmah, D. and Varley, I.: Hydrologic modelling practices for estimating low flows - guidelines, National Water Commission, Canberra, 2012.

Barredo, J. I.: No upward trend in normalised windstorm losses in Europe: 1970-2008, Nat. Hazards Earth Syst. Sci., 10, 97-104, https://doi.org/10.5194/nhess-10-97-2010, 2010.

Bartholmes, J. C., Thielen, J., Ramos, M. H., and Gentilini, S.: The european flood alert system EFAS - Part 2: Statistical skill assessment of probabilistic and deterministic operational forecasts, Hydrol. Earth Syst. Sci., 13, 141-153, https://doi.org/10.5194/hess-13-141-2009, 2009. 
Bates, P. D., Pappengberger, F., and Romanowicz, R. J.: Uncertainties in flood inundation modelling, in: Applied Uncertainty Analysis for Flood Risk Management, edited by: Beven, K. J. and Hall, J. W., Imperial College Press: London, 232-269, 2014.

Begnudelli, L. and Sanders, B. F.: Simulation of the St. Francis dam-break flood, J. Eng. Mechan., 133, 1200-1212, 2007.

Berry, R., Horritt, M., Dewar, C. Baigent, S., and Martin, J.: Development of flood mapping formats for the Lee ctchment flood risk assessment and management study, in: Proc. National Hydrology Seminar, 2008, Hydrology in Spatial Planning and Development, Irish National Committee IHP, 2008.

Beven, K. J.: Towards the use of catchment geomorphology in flood frequency predictions, Earth Surf. Process. Landf., V12, 69-82, 1987.

Beven, K. J.: Environmental Modelling - An Uncertain Future?, Routledge: London, 2009.

Beven, K. J.: Causal models as multiple working hypotheses about environmental processes, Comptes Rendus Geoscience, Académie de Sciences, Paris, 344, 77-88, https://doi.org/10.1016/j.crte.2012.01.005, 2012.

Beven, K. J.: So how much of your error is epistemic? Lessons from Japan and Italy, Hydrol. Process., 27, 1677-1680, https://doi.org/10.1002/hyp.9648, 2013

Beven, K. J.: EGU Leonardo Lecture: Facets of Hydrology epistemic error, non-stationarity, likelihood, hypothesis testing, and communication, Hydrol. Sci. J., 61, 1652-1665, https://doi.org/10.1080/02626667.2015.1031761, 2016.

Beven, K. J. and Alcock, R.: Modelling everything everywhere: a new approach to decision making for water management under uncertainty, Freshw. Biol., 56, 124-132, 2012.

Beven, K. J. and Lamb, R.: The uncertainty cascade in model fusion, in: Integrated Environmental Modelling to Solve Real World Problems: Methods, Vision and Challenges, edited by: Riddick, A. T., Kessler, H., and Giles, J. R. A., Geological Society, London, Special Publication 408, https://doi.org/10.1144/SP408.3, 2014.

Beven, K., Lamb, R., Leedal, D., and Hunter, N.: Communicating uncertainty in flood inundation mapping: a case study, Int. J. River Basin Manage., 13, 285-295, https://doi.org/10.1080/15715124.2014.917318, 2015.

Beven, K. J., Aspinall, W. P., Bates, P. D., Borgomeo, E., Goda, K., Hall, J. W., Page, T., Phillips, J. C., Simpson, M., Smith, P. J., Wagener, T., and Watson, M.: Epistemic uncertainties and natural hazard risk assessment - Part 2: What should constitute good practice?, Nat. Hazards Earth Syst. Sci., 18, 2769-2783, https://doi.org/10.5194/nhess-18-2769-2018, 2018.

Beven, K., and Young, P.: A guide to good practice in modeling semantics for authors and referees, Water Resour. Res., 49, 5092 5098, https://doi.org/10.1002/wrcr.20393, 2013.

Blauhut, V., Gudmundsson, L., and Stahl, K.: Towards panEuropean drought risk maps: quantifying the link between drought indices and reported drought impacts, Environ. Res. Lett., 10, 1-10, https://doi.org/10.1088/1748-9326/10/1/014008, 2015.

Blazkova, S. and Beven, K. J.: Flood frequency estimation by continuous simulation of subcatchment rainfalls and discharges with the aim of improving dam safety assessment in a large basin in the Czech Republic, J. Hydrol., 292, 153-172, 2004.
Blazkova, S. and Beven, K. J.: A limits of acceptability approach to model evaluation and uncertainty estimation in flood frequency estimation by continuous simulation: Skalka catchment, Czech Republic, Water Resour. Res., 45, W00B16, https://doi.org/10.1029/2007WR006726, 2009.

Bloomfield, J. P. and Marchant, B. P.: Analysis of groundwater drought building on the standardised precipitation index approach, Hydrol. Earth Syst. Sci., 17, 4769-4787, https://doi.org/10.5194/hess-17-4769-2013, 2013.

Blöschl, G., Sivapalan, M., Wagener, T., Viglione, A., and Savenije, H.: Runoff Prediction in Ungauged Basins: Synthesis across Processes, Places and Scales, Cambridge University Press: Cambridge, 2013.

Bommer, J. J.: Challenges of building logic trees for probabilistic seismic hazard analysis, Earthq. Spec., 28, 1723-1735, 2012.

Bonadonna, C. and Houghton, B. F.: Total grain-size distribution and volume of tephra-fall deposits, Bull. Volcanol., 67, 441-456, 2005.

Bonazzi, A., Cusack, S., Mitas, C., and Jewson, S.: The spatial structure of European wind storms as characterized by bivariate extreme-value Copulas, Nat. Hazards Earth Syst. Sci., 12, 1769_ 1782, https://doi.org/10.5194/nhess-12-1769-2012, 2012.

Borgomeo, E., Hall, J. W., Fung, F., Watts, G., Colquhoun, K., and Lambert, C.: Risk-based water resources planning: Incorporating probabilistic nonstationary climate uncertainties, Water Resour Res., 50, 6850-6873, https://doi.org/10.1002/2014WR015558, 2014.

Brodin, E. and Rootzén, H.: Univariate and bivariate GPD methods for predicting extreme wind storm losses, Insurance: Mathe. Econom., 44, 345-356, 2009.

Brown, J. D.: Knowledge, uncertainty and physical geography: towards the development of methodologies for questioning belief, Trans. Inst. Br. Geogr., 29, 367-381, 2004.

Brown, J. D.: Prospects for the open treatment of uncertainty in environmental research, Prog. Phys. Geog., 34, 75-100, 2010.

Budnitz, R. J., Apostolakis, G., Boore, D. M., Cluff, L. S., Coppersmith, K. J., Cornell, C. A., and Morris, P. A.: Recommendations for probabilistic seismic hazard analysis: guidance on the uncertainty and use of experts, NUREG/CR-6372, U.S. Nuclear Regulatory Commission, Washington, D.C., 1997.

Bürgmann, R. and Chadwell, D.: Seafloor geodesy, Annu. Rev. Earth Planet. Sci., 42, 509-534, 2014.

Bursik, M. I., Carey, S. N., and Sparks, R. S. J.: A gravity current mode for the May 18, 1980 Mount St. Helens plume, Geophys. Res. Lett., 19, 1663-1666, 1992a.

Bursik, M. I., Sparks, R. S. J., Gilbert, J. S., and Carey, S. N.: Sedimentation of tephra by volcanic plumes: I. Theory and its comparison with a study of the Fogo A plinian deposit, Sao Miguel (Azores), Bull. Volcanol., 54, 329-344, 1992b.

Cameron, D., Beven, K. J., Tawn, J., Blazkova, S., and Naden, P.: Flood frequency estimation by continuous simulation for a gauged upland catchment (with uncertainty), J. Hydrol., 219, 169-187, 1999.

Cameron, D., Beven, K., and Naden, P.: Flood frequency estimation by continuous simulation under climate change (with uncertainty), Hydrol. Earth Syst. Sci., 4, 393-405, https://doi.org/10.5194/hess-4-393-2000, 2000. 
Cao, Z., Pender, G., Wallis, S., and Carling, P.: Computational dambreak hydraulics over erodible sediment bed, ASCE J. Hydraul. Eng., 130, 689-703, 2004.

Catto, J. L., Shaffrey, L. C., and Hodges, K. I.: Can climate models capture the structure of extratropical cyclones?, J. Climate, 23, 1621-1635, 2010.

Cepeda, J., Colonnelli, S., Meyer, N. K., and Kronholm, K.: SafeLand Deliverable D1.5: Statistical and empirical models for prediction of precipitation-induced landslides, available at: http: //www.safeland-fp7.eu/ (last access: October 2018), 2012.

Chandler, R. E., Isham, V. S., Northrop, P. J., Wheater, H. S., Onof, C. J., and Leith, N. A.: Uncertainty in rainfall inputs, in: Applied Uncertainty Analysis for Flood Risk Management, edited by: Beven, K. J. and Hall, J. W., Imperial College Press: London, 101-152, 2014

Chatterton, J., Penning-Rowsell, E., and Priest, S.: The many uncertainties in flood loss assessments, in: Applied Uncertainty Analysis for Flood Risk Management, edited by: Beven, K. J. and Hall, J. W., Imperial College Press: London, 335-356, 2014.

Cho, S. E.: Effects of spatial variability of soil properties on slope stability, Eng. Geol., 92, 97-109, https://doi.org/10.1016/j.enggeo.2007.03.006, 2007.

Christian, J. T., Ladd, C. C., and Baecher, G. B.: Reliability applied to slope stability analysis, ASCE J. Geotech. Eng., 120, 2180-2207, https://doi.org/10.1061/(asce)07339410(1994)120:12(2180), 1994.

Cioni, R., Bertagnini, A., Santacroce, R., and Andronico, D.: Explosive activity and eruption scenarios at Somma-Vesuvius (Italy): Towards a new classification scheme, J. Volcanol. Geotherm. Res., 178, 331-346, https://doi.org/10.1016/j.jvolgeores.2008.04.024, 2008.

Cornell, C. A.: Engineering seismic risk analysis, B. Seismol. Soc. Am., 58, 1583-1606, 1968.

Cornell, C. A. and Winterstein, S. R.: Temporal and magnitude dependence in earthquake recurrence models, B. Seismol. Soc. Am., 78, 1522-1537, 1988 .

Corominas, J., van Westen, C., Frattini, P., Cascini, L., Malet, J. P., Fotopoulou, S., Catani, F., Van Den Eeckhaut, M., Mavrouli, O., Agliardi, F., Pitilakis, K., Winter, M. G., Pastor, M., Ferlisi, S., Tofani, V., Hervas, J., and Smith, J. T.: Recommendations for the quantitative analysis of landslide risk, B. Eng. Geol. Environ., 73, 209-263, https://doi.org/10.1007/s10064-013-0538-8, 2014.

Costa, A., Folch, A., and Macedonio, G.: Density-driven transport in the umbrella region of volcanic clouds: Implications for tephra dispersion models, Geophys. Res. Lett., 40, 4823-4827, 2013.

Cox, R. T.: Probability ,frequency and reasonable expectation, Am. J. Phys., 14, 1-13, https://doi.org/10.1119/1.1990764, 1946.

Cox Jr., L. A.: Confronting deep uncertainties in risk analysis, Risk Anal., 32, 1607-1629, 2012.

Coxon, G., Freer, J., Westerberg, I. K., Wagener, T., Woods, R., and Smith, P. J.: A novel framework for discharge uncertainty quantification applied to 500 UK gauging stations, Water Resour. Res., 51, 5531-5546, https://doi.org/10.1002/2014WR016532, 2015.

Crovelli, R. A.: Probabilistic models for estimation of number and cost of landslides, Open-File Report 00-249, US Geological Survey, available at: http://pubs.usgs.gov/of/2000/ofr-00-0249/ ProbModels.html (last access: October 2018), 2000.
Dacre, H. F., Harvey, N. J., Webley, P. W., and Morton, D.: How accurate are volcanic ash simulations of the 2010 Eyjafjallajökull eruption?, J. Geophys. Res.-Atmos., 121, 3534-3547, 2016.

Day, S. and Fearnley, C.: A classification of mitigation strategies for natural hazards: implications for the understanding of interactions between mitigation strategies, Nat. Hazards, 79, 12191238, 2015.

de Finetti, B.: La Prévision: ses lois logiques, ses sources subjectives, Annales de l'Institut Henri Poincaré, 1937.

de Finetti, B.: Theory of Probability, (trans. A Machi and AFM Smith) 2 volumes, Wiley: New York, 1974.

Della-Marta, P. M., Mathis, H., Frei, C., Liniger, M. A., Kleinn, J., and Appenzeller, C.: The return period of wind storms over Europe, Int. J. Climatol., 29, 437-459, 2009.

Della-Marta, P. M., Liniger, M. A., Appenzeller, C., Bresch, D. N., Köllner-Heck, P., and Muccione, V.: Improved estimates of the European winter windstorm climate and the risk of reinsurance loss using climate model data, J. Appl. Meteorol. Climatol., 49, 2092-2120, 2010.

Denlinger, R. P., Pavolonis, M. J., and Sieglaff, J.: A robust method to forecast volcanic ash clouds, J. Geophys. Res., 117, D13208, https://doi.org/10.1029/2012JD017732, 2012.

De Risi, R. and Goda, K.: Probabilistic earthquake-tsunami multihazard analysis: application to the Tohoku region, Japan, Front. Built Environ., 2, 25, https://doi.org/10.3389/fbuil.2016.00025, 2016.

De Roo, A., Thielen, J., Salamon, P., Bogner, K., Nobert, S., Cloke, H., Demeritt, D., and Pappenberger, F.: Quality control, validation and user feedback of the European Flood Alert System (EFAS), Int. J. Digit. Earth, 4 (Sup1), 77-90, 2011.

Devenish, B. J., Francis, P. N., Johnson, B. T., Sparks, R. S. J., and Thomson, D. J.: Sensitivity analysis of dispersion modeling of volcanic ash from Eyjafjallajökull in May 2010, J. Geophys. Res., 117, D00U21, https://doi.org/10.1029/2011JD016782, 2012a.

Devenish, B. J., Thomson, D. J., Marenco, F., Leadbetter, S. J., Ricketts, H., and Dacre, H. F.: A study of the arrival over the United Kingdom in April 2010 of the Eyjafjallajökull ash cloud using ground-based lidar and numerical simulations, Atmos. Environ., 48, 152-164, 2012b.

DPC: Pianificazione Nazionale d'Emergenza dell'Area Vesuviana, Dipartimento della Protezione Civile, Presidenza del Consiglio dei Ministri. Rome, 157 pp., 1995 (in Italian).

DPC: Proposta di aggiornamento della Pianificazione Nazionale d'Emergenza dell'Area Vesuviana, Dipartimento della Protezione Civile, Presidenza del Consiglio dei Ministri, Rome, 55 pp., 2001 (in Italian).

Duan, K. and Mei, Y.: Comparison of Meteorological, Hydrological and Agricultural Drought Responses to Climate Change and Uncertainty Assessment, Water Resour. Manage., 28, 5039-5054, 2014.

Dussauge-Peisser, C., Helmstetter, A., Grasso, J.-R., Hantz, D., Desvarreux, P., Jeannin, M., and Giraud, A.: Probabilistic approach to rock fall hazard assessment: potential of historical data analysis, Nat. Hazards Earth Syst. Sci., 2, 15-26, https://doi.org/10.5194/nhess-2-15-2002, 2002.

Eagleson, P. S.: Dynamics of flood frequency, Water Resour. Res., 8, 878-898, 1972. 
El-Ramly, H., Morgenstern, N. R., and Cruden, D. M.: Probabilistic slope stability analysis for practice, Canad. Geotech. J., 39, 665683, https://doi.org/10.1139/T02-034, 2002.

Eastoe, E. F. and Tawn, J. A.: Statistical models for overdispersion in the frequency of peaks over threshold data from UK flow series, Water Resour. Res., 46, W02510, https://doi.org/10.1029/2009WR007757, 2010.

Ercanoglu, M. and Gokceoglu, C.: Assessment of landslide susceptibility for a landslide-prone area (north of Yenice, NW Turkey) by fuzzy approach, Environ. Geol., 41, 720-730, https://doi.org/10.1007/s00254-001-0454-2, 2002.

Economou, T., Stephenson, D. B., and Ferro, C. A.: Spatio-temporal modelling of extreme storms, The Annal. Appl. Stat., 8, 2223 2246, 2014.

Esposti Ongaro, T., Cavazzoni, C., Erbacci, G., Neri, A., and Salvetti, M. V.: A parallel multiphase flow code for the 3D simulation of explosive volcanic eruptions, Parall. Comp., 33, 541-560, 2007.

Esposti Ongaro, T., Neri, A., Menconi, G., De'Michieli Vitturi, M., Marianelli, P., Cavazzoni, C., Erbacci, G., and Baxter, P. J.: Transient 3D numerical simulations of column collapse and pyroclastic flow scenarios at Vesuvius, J. Volcanol. Geotherm. Res., 178, 378-396, https://doi.org/10.1016/j.jvolgeores.2008.06.036, 2008.

Folch, A., Costa, A., and Basart, S.: Validation of the FALL3D ash dispersion model using observations of the 2010 Eyjafjallajökull volcanic ash clouds, Atmos. Environ., 48, 165-183, 2012.

Francis, P. N., Cooke, M. C., and Saunders, R. W.: Retrieval of physical properties of volcanic ash using Meteosat: A case study from the 2010 Eyjafjallajökull eruption, J. Geophys. Res., 117, D00U09, https://doi.org/10.1029/2011JD016788, 2012.

Gariano, S. L., Brunetti, M. T., Iovine, G., Melillo, M., Peruccacci, S., Terranova, O. G., Vennari, C., and Guzzetti, F.: Calibration and validation of rainfall thresholds for shallow landslide forecating in Sicily, Southern Italy, Geomorphology, 228, 653-665, https://doi.org/10.1007/s11069-014-1129-0, 2015.

Gallegos, H. A., Schubert, J. E., and Sanders, B. F.: Twodimensional, high-resolution modeling of urban dam-break flooding: a case study of Baldwin Hills, California, Adv. Water Resour., 32, 1323-1335, 2009.

Gens, A.: Soil-environment interactions in geotechnical engineering, Geotechnique, 60, 3-74, https://doi.org/10.1680/Geot.9.P.109, 2010.

Gill, J. C. and Malamud, B.: Reviewing and visualizing the interactions of natural hazards, Rev. Geophys., 52.4, 680-722, 2014.

Goda, K. and Hong, H. P.: Optimal seismic design for limited planning time horizon with detailed seismic hazard information, Struct. Safety, 28, 247-260, 2006.

Goda, K., Mai, P. M., Yasuda, T., and Nobuhito Mori, N.: Sensitivity of tsunami wave profile and inundation simulations to earthquake slip and fault geometry for the 2011 Tohoku earthquake, Earth Planet. Space, 66, 105, https://doi.org/10.1186/1880-598166-105, 2014.

Goda, K., Yasuda, T., Mori, N., and Maruyama, T.: New scaling relationships of earthquake source parameters for stochastic tsunami simulation, Coast. Eng. J., 58, 1650010, https://doi.org/10.1142/S0578563416500108, 2016.

Goda, K., De Risi, R., and Rossetto, T.: Stochastic coupled simulation of strong motion and tsunami for the 2011 Tohoku, Japan earthquake, Stoch. Environ. Res. Risk Assess., 31, 2337-2355, 2017.

Goda, K. and Song, J.: Uncertainty modeling and visualization for tsunami hazard and risk mapping: a case study for the 2011 Tohoku earthquake, Stoch. Environ. Res. Risk Assess., 30, $2271-$ 2285, 2016.

Goldfinger, C., Nelson, C. H., Morey, A. E., Johnson, J. E., Patton, J., Karabanov, E., Gutierrez-Pastor, J., Eriksson, A. T., Gracia, E., Dunhill, G., Enkin, R. J., Dallimore, A., and Vallier, T.: Turbidite event history - methods and implications for Holocene paleoseismicity of the Cascadia subduction zone, U.S. Geological Survey Professional Paper 1661-F, 170 p., 2012.

Gouldby, B. P., Sayers, P. B., Panzeri, M. C., and Lanyon, J. E.: Development and application of efficient methods for the forward propagation of epistemic uncertainty and sensitivity analysis within complex broad-scale flood risk system models T, Can. J. Civil Eng., 37, 955-967, 2010.

Griffiths, D. V. and Fenton, G. A.: Probabilistic slope stability analysis by finite elements, J. Geotech. Geoenviron. Eng., 130, 507518, https://doi.org/10.1061/(asce)1090-0241(2004)130:5(507), 2004.

Griffiths, D. V., Huang, J. S., and Fenton, G. A.: Influence of Spatial Variability on Slope Reliability Using 2-D Random Fields, J. Geotech. Geoenviron. Eng., 135, 1367-1378, https://doi.org/10.1061/(asce)gt.1943-5606.0000099, 2009.

Guzzetti, F., Carrara, A., Cardinali, M., and Reichenbach, P.: Landslide hazard evaluation: a review of current techniques and their application in a multi-scale study, Central Italy, Geomorphology, 31, 181-216, https://doi.org/10.1016/S0169-555x(99)00078-1, 1999.

Guzzetti, F., Reichenbach, P., Cardinali, M., Galli, M., and Ardizzone, F.: Probabilistic landslide hazard assessment at the basin scale, Geomorphology, 72, 272-299, https://doi.org/10.1016/j.geomorph.2005.06.002, 2005.

Guzzetti, F., Reichenbach, P.. Ardizzone, F., Cardinali, M., and Galli, M.: Estimating the quality of landslide susceptibility models, Geomorphology, 81, 166-184, https://doi.org/10.1016/j.geomorph.2006.04.007, 2006.

Hall, J. W., Rubio, E., and Anderson, M. G.: Random sets of probability measures in slope hydrology and stability analysis, ZAMM: J. Appl. Mathe. Mechan., 84, 710-720, 2004.

Hall, J. W., Manning, L. J., and Hankin, R. K.: Bayesian calibration of a flood inundation model using spatial data, Water Resour. Res., 47, W05529, https://doi.org/10.1029/2009WR008541, 2011.

Hall, J. W., Watts, G., Keil, M., de Vial, L., Street, R., Conlan, K., O'Connell, P. E., Beven, K. J., and Kilsby, C. J.: Towards risk-based water resources planning in England and Wales under a changing climate, CIWEM Water Environ. J., 26, 118-129, https://doi.org/10.1111/j.1747-6593.2011.00271.x, 2012.

Haneberg, W. C.: A rational probabilistic method for spatially distributed landslide hazard assessment, Environ. Eng. Geosci., 10, 27-43, https://doi.org/10.2113/10.1.27, 2004.

Harou, J. J., Medellín-Azuara, J., Zhu, T., Tanaka, S. K. Lund, J. R., Stine, S., Olivares, M. A., and Jenkins, M. W.: Economic consequences of optimized water management for a prolonged, severe drought in California, Water Resour. Res., 46, W05522, https://doi.org/10.1029/2008WR007681, 2010. 
Hartmann, A., Gleeson, T., Wada, Y., and Wagener, T.: Enhanced recharge rates by altered recharge sensitivity to climate variability through subsurface heterogeneity, P. Natl. Acad. Sci. USA, 114, 2842-2847, https://doi.org/10.1073/pnas.1614941114, 2017.

Harvey, N. J., Huntley, N., Dacre, H. F., Goldstein, M., Thomson, D., and Webster, H.: Multi-level emulation of a volcanic ash transport and dispersion model to quantify sensitivity to uncertain parameters, Nat. Hazards Earth Syst. Sci., 18, 41-63, https://doi.org/10.5194/nhess-18-41-2018, 2018.

Helton, J. C. and Burmaster, D. E.: Guest editorial: treatment of aleatory and epistemic uncertainty in performance assessments for complex systems, Reliab. Eng. Syst. Safe., 54, 91-94, 1996.

Hencher, S. R.: Preferential flow paths through soil and rock and their association with landslides, Hydrol. Process., 24, 1610 1630,2010

Hervouet, J. M. and Petitjean, A.: Malpasset dam-break revisited with two-dimensional computations, J. Hydraul. Res., 37, 777788, 1999.

Hobbs, P. V., Radke, L. F., Lyons, J. H., Ferek, R. J., Coffman, D. J., and Casadevall, T. J.: Airbourne measurements of particle and gas emissions from the 1990 volcanic eruptions of Mount Redoubt, J. Geophys. Res., 96, 735-752, 1991.

Hodge, M., Biggs, J., Goda, K., and Aspinall, W. P.: Assessing infrequent large earthquakes using geomorphology and geodesy: the Malawi Rift, Nat. Hazards , 76, 1781-1806, 2015.

Hoffman, F. O. and Hammonds, J. S.: Propagation of uncertainty in risk assessments: the need to distinguish between uncertainty due to lack of knowledge and uncertainty due to variability, Risk Anal., 14, 707-712, 1994

Holcombe, E., Smith, S., Wright, E., and Anderson, M. G.: An integrated approach for evaluating the effectiveness of landslide risk reduction in unplanned communities in the Caribbean, Nat. Hazards, 61, 351-385, https://doi.org/10.1007/s11069-011-9920-7, 2012.

Hong, X., Guo, S., Zhou, Y., and Xiong, L.: Uncertainties in assessing hydrological drought using streamflow drought index for the upper Yangtze River basin, Stoch. Environ. Res. Risk Assess., 29, 1235-1247, https://doi.org/10.1007/s00477-014-0949$5,2014$.

Horspool, N., Pranantyo, I., Griffin, J., Latief, H., Natawidjaja, D. H., Kongko, W., Cipta, A., Bustaman, B., Anugrah, S. D., and Thio, H. K.: A probabilistic tsunami hazard assessment for Indonesia, Nat. Hazards Earth Syst. Sci., 14, 3105-3122, https://doi.org/10.5194/nhess-14-3105-2014, 2014.

House-Peters, L. A. and Chang, H.: Urban water demand modeling: Review of concepts, methods, and organizing principles, Water Resour. Res., 47, W05401, https://doi.org/10.1029/2010WR009624, 2011.

Hrachowitz, M., Savenije, H. H. S., Bloschl, G., McDonnell, J., Sivapalan, M., Pomeroy, J., Arheimer, B., Blume, T., Clark, M., Ehret, U., Fenicia, F., Freer, J., Gelfan, A., Gupta, H., Hughes, D., Hut, R., Montanari, A., Pande, S., Tetzlaff, D., Troch, P., Uhlenbrook, S., Wagener, T., Winsemius, H., Woods, R., Zehe, E., and Cudennec, C.: A decade of Predictions in Ungauged Basins (PUB) - a review, Hydrol. Sci. J., 58, 1-58, https://doi.org/10.1080/02626667.2013.803183, 2013.

Hu, Y.-M., Liang, Z.-M., Liu, Y.-W., Wang, J., Yao, L., and Ning, Y.: Uncertainty analysis of SPI calculation and drought assessment based on the application of Bootstrap, Int. J. Climatol., 35, $1847-$ 1857, https://doi.org/10.1002/joc.4091, 2014.

Hungr, O., Evans, S. G., and Harzard, J.: Magnitude and frequency of rock falls and rock slides along the main transportation corridors of southwestern British Columbia, Canad. Geotech. J., 36, 224-238, https://doi.org/10.1139/Cgj-36-2-224, 1999.

Hürlimann, M., Rickenmann, D., Medina, V., and Bateman, A.: Evaluation of approaches to calculate debris-flow parameters for hazard assessment, Eng. Geol., 102, 152-163, 2008.

ICOLD: Dam Failures, Statistical Analysis, Bulletin 99, Commission Internationale des Grands Barrages, Paris, 73 pp., 1995.

IH: The Flood Estimation Handbook, (5 vols.), Institute of Hydrology: Wallingford, UK, 1999.

Jenkins, K.: Indirect economic losses of drought under future projections of climate change: a case study for Spain, Nat. Hazards, 69, 1967-1986, 2013

Johnes, M., Aberfan and the Management of Trauma: Disasters, 24, 1-17, https://doi.org/10.1111/1467-7717.00128, 2000.

Jones, A. R., Thomson, D. J., Hort, M. C., and Devenish, B. J.: The U.K. Met Offices Next-Generation Atmospheric Dispersion Model, NAME III, Air Pollut. Model. Appl., XVII 6, 580-589, 2007.

Jongman, B., Kreibich, H., Apel, H., Barredo, J. I., Bates, P. D., Feyen, L., Gericke, A., Neal, J., Aerts, J. C. J. H., and Ward, P. J.: Comparative flood damage model assessment: towards a European approach, Nat. Hazards Earth Syst. Sci., 12, 3733-3752, https://doi.org/10.5194/nhess-12-3733-2012, 2012.

Jorgensen, B., Graymore, M., and O'Toole, K.: Household water use behaviour: An integrated model, J. Environ. Manage., 91, 227-236, 2009.

Kagan, Y. Y. and Jackson, D. D.: Tohoku earthquake: a surprise?, B. Seismol. Soc. Am., 103, 1181-1191, 2013

Kaiser, G., Scheele, L., Kortenhaus, A., Løvholt, F., Römer, H., and Leschka, S.: The influence of land cover roughness on the results of high resolution tsunami inundation modeling, Nat. Hazards Earth Syst. Sci., 11, 2521-2540, https://doi.org/10.5194/nhess11-2521-2011, 2011.

Karremann, M. K., Pinto, J. G., Reyers, M., and Klawa, M.: Return periods of losses associated with European windstorm series in a changing climate, Environ. Res. Lett., 9, 124016 , https://doi.org/10.1088/1748-9326/9/12/124016, 2014.

Kasprzyk, J. R., Reed, P. M., Kirsch, B. R., and Characklis, G. W.: Managing population and drought risks using many-objective water portfolio planning under uncertainty, Water Resour. Res., 45, W12401, https://doi.org/10.1029/2009WR008121, 2009.

Keef, C., Tawn, J. A., and Lamb. R.: Estimating the probability of widespread flood events, Environmetrics, 24.1, 13-21, 2013.

Keefer, D. K., Wilson, R. C., Mark, R. K.. Brabb, E. E., Brown, W. M., Ellen, S. D. , Harp, E. L., Wieczorek, G. F., Alger, C. S., and Zatkin, R. S.: Real-time landslide warning during heavy rainfall, Science, 238, 921-925, https://doi.org/10.2307/1700926, 1987.

Kenney, D. S., Goemans, C., Klein, R., Lowrey, J., and Reidy, K.: Residential Water Demand Management: Lessons from Aurora, Colorado, JAWRA J. Am. Water Resour. Assoc., 44, 192-207, https://doi.org/10.1111/j.1752-1688.2007.00147.x, 2008.

Keynes, J. M.: Treatise on Probability, Macmillan \& Co.: London, 1921.

Khare, S., Bonazzi, A., Mitas, C., and Jewson, S.: Modelling clustering of natural hazard phenomena and the effect on re/insurance 
loss perspectives, Nat. Hazards Earth Syst. Sci., 15, 1357-1370, https://doi.org/10.5194/nhess-15-1357-2015, 2015.

Knight, F. H.: Risk, Uncertainty and Profit, Houghton-Mifflin Co. (reprinted University of Chicago Press, 1971), Boston, MA, 1921.

Koshimura, S., Oie, T., Yanagisawa, H., and Imamura, F.: Developing fragility functions for tsunami damage estimation using numerical model and post-tsunami data from Banda Aceh, Indonesia, Coast. Eng. J., 51, 243-273, 2009.

Koutsoyiannis, D.: Climate change, the Hurst phenomenon, and hydrological statistics, Hydrol. Sci. J., 48, 3-24, https://doi.org/10.1623/hysj.48.1.3.43481, 2003.

Koutsoyiannis, D.: HESS Opinions “A random walk on water”, Hydrol. Earth Syst. Sci., 14, 585-601, https://doi.org/10.5194/hess14-585-2010, 2010.

Koutsoyiannis, D. and Montanari, A.: Statistical analysis of hydroclimatic time series: Uncertainty and insights, Water Resour. Res., 43, W05429, https://doi.org/10.1029/2006WR005592, 2007.

Kristiansen, N. I., Stohl, A., Prata, A. J., Bukowiecki, N., Dacre, H. F., Eckhardt, S., Henne, S., Hort, M. C., Johnson, B. T., Marenco, F., Neininger, B., Reitebuch, O., Seibert, P., Thomson, D. J., Webster, H. N., and Weinzierl, B.: Performance assessment of a volcanic ash transport model mini-ensemble used for inverse modeling of the 2010 Eyjafjallajökull eruption, J. Geophys. Res., 117, D00U11, https://doi.org/10.1029/2011JD016844, 2012.

Kulkarni, R. B., Youngs, R. R., and Coppersmith, K. J.: Assessment of confidence intervals for results of seismic hazard analysis, Proc. Eighth World Conf. Earthq. Eng., 1, 263-270, 1984.

Lamb, R. and Kay, A. L.: Confidence intervals for a spatially generalized, continuous simulation flood frequency model for Great Britain, Water Resour. Res., 40, W07501, https://doi.org/10.1029/WR002428, 2004.

Lamb, R., Keef, C., Tawn, J., Laeger, S., Meadowcroft, I., Surendran, S., Dunning, P., and Batstone, C.: A new method to assess the risk of local and widespread flooding on rivers and coasts, J. Flood Risk Manage., 3, 323-336, 2010.

Lamb, R., Aspinall, W., Odbert, H., and Wagener, T.: Vulnerability of bridges to scour: insights from an international expert elicitation workshop, Nat. Hazards Earth Syst. Sci., 17, 1393-1409, https://doi.org/10.5194/nhess-17-1393-2017, 2017.

Lavallee, D., Liu, P., and Archuleta, R. J.: Stochastic model of heterogeneity in earthquake slip spatial distributions, Geophys. J. Int., 165, 622-640, 2006.

Lee, E. M. and Jones, D. K. C.: Landslide Risk Assessment, Thomas Telford Publishing, London, 2004.

Lee, K. H., Wong, M. S., Chung, S.-R., and Sohn, E.: Improved volcanic ash detection based on a hybrid reverse absorption technique, Atmos. Res., 143, 31-42, 2014.

Lin, J. W., Chen, C. W., and Peng, C. Y.: Potential hazard analysis and risk assessment of debris flow by fuzzy modeling, Nat. Hazards, 64. 273-282, https://doi.org/10.1007/s11069-012-0236-z, 2012.

López López, P., Verkade, J. S., Weerts, A. H., and Solomatine, D. P.: Alternative configurations of quantile regression for estimating predictive uncertainty in water level forecasts for the upper Severn River: a comparison, Hydrol. Earth Syst. Sci., 18, 34113428, https://doi.org/10.5194/hess-18-3411-2014, 2014.
Ludwig, P., Pinto, J. G., Reyers, M., and Gray, S. L.: The role of anomalous SST and surface fluxes over the southeastern North Atlantic in the explosive development of windstorm Xynthia, Q. J. Roy. Meteorol. Soc., 140, 1729-1741, 2014.

Løvholt, F., Glimsdal, S., Harbitz, C.B., Horspool, N., Smebye, H., de Bono, A., and Nadim, F.: Global tsunami hazard and exposure due to large co-seismic slip, Int. J. Disaster Risk Reduc., 10, 406418, 2014.

Mackie, S., Millington, S. C., and Watson, I. M.: How assumed composition affects the interpretation of satellite observations of volcanic ash, Meteorol. Appl., 21, 20-29, 2014.

Mackie, S. and Watson I. M.: The atmospheric dependency of the sensitivity of infrared satellite observations to thin volcanic ash clouds, J. Appl. Remote Sens., 9, 095080, https://doi.org/10.1117/1.JRS.9.095080, 2015.

Mai, P. M. and Beroza, G. C.: A spatial random field model to characterize complexity in earthquake slip, J. Geophys. Res.-Solid Earth, 107, 2308, https://doi.org/10.1029/2001JB000588, 2002.

Mailier, P. J., Stephenson, D. B., Ferro, C. A., and Hodges, K. I.: Serial clustering of extratropical cyclones, Mon. Weather Rev., 134, 2224-2240, 2006.

Marsh, T., Cole, G., and Wilby, R.: Major droughts in England and Wales, 1800-2006, Weather, 62, 87-93, https://doi.org/10.1002/wea.67, 2007.

Marzocchi, W. and Jordan, T. H.: Testing for ontological errors in probabilistic forecasting models of natural systems, P. Natl. Acad. Sci. USA, 111, 11973-11978, 2014.

Mastin, L. G., Guffanti, M., Servranckx, R., Webley, P. W., Barsotti, S., Dean, K., Durant, A., Ewert, J. W., Neri, A., Rose, W. I., Schneider, D. J., Siebert, L., Stunder, B., Swanson, G., Tupper, A., Volentik, A., and Waythomas, C. F.: A multidisciplinary effort to assign realistic source parameters to models of volcanic ash-cloud transport and dispersion during eruptions, J. Volcanol. Geotherm. Res., 186, 10-21, 2009.

Matthews, M. V., Ellsworth, W. L., and Reasenberg, P. A.: A Brownian model for recurrent earthquakes, Bull. Seismol. Soc. Am., 92, 2233-2250, 2002.

Mazzocchi, M., Hansstein, F., and Ragona, M.: The 2010 volcanic ash cloud and its impact on the european airline industry, in: The economic impacts of air travel restrictions due to volcanic ash, CESifo Forum, 2/2010, Oxford Economics, 2010.

McCaffrey, R., King, R. W., Payne, S. J., and Lancaster, M.: Active tectonics of Northwestern US inferred from GPSderived surface velocities, J. Geophys. Res., 118, 709-723, https://doi.org/10.1029/2012JB009473, 2013.

McGuire, R.: Deterministic vs Probabilistic Earthquake Hazards and Risks, Soil Dynam. Earthq. Eng., 21, 377-384, 2001.

McGuire, R. K.: Seismic hazard and risk analysis, Earthquake Engineering Research Institute, Oakland, CA, 2004.

McIntyre, N., Lee, H., Wheater, H. S., Young, A., and Wagener, T.: Ensemble prediction of runoff in ungauged watersheds, Water Resour. Res., 41, W12434, https://doi.org/10.1029/2005WR004289, 2005.

McMillan, H. K. and Westerberg, I. K.: Rating curve estimation under epistemic uncertainty, Hydrol. Process., 29, 1873-1882, 2015.

Mechler, R., Hochrainer, S., Aaheim, A., Salen, H., and Wreford, A.: Modelling economic impacts and adaptation to extreme events: Insights from European case studies, Mitigation 
and Adaptation Strategies for Global Change, 15, 737-762, https://doi.org/10.1007/s11027-010-9249-7, 2010.

Millington, S. C., Saunders, R. W., Francis, P. N., and Webster, H. N.: Simulated volcanic ash imagery: A method to compare NAME ash concentration forecasts with SEVIRI imagery for the Eyjafjallajökull eruption in 2010, J. Geophys. Res., 117, D00U17, https://doi.org/10.1029/2011JD016770, 2012.

Montanari, A. and Koutsoyiannis, D.: A blueprint for process-based modeling of uncertain hydrological systems, Water Resour. Res., 48, W09555, https://doi.org/10.1029/2011WR011412, 2012.

Moxnes, E. D., Kristiansen, N. I., Stohl, A., Clarisse, L., Durant, A., Weber K., and Vogel, A.: Separation of ash and sulfur dioxide during the 2011 Grímsvötn eruption, J. Geophys. Res.-Atmos., 119, 7477-7501, https://doi.org/10.1002/2013JD021272, 2014.

Mulargia, F., Stark, P. B., and Geller, R. J.: Why is probabilistic seismic hazard analysis (PSHA) still used?, Phys. Earth Planet. Inter., 264, 63-75, 2017.

Murray, J. and Segall, P.: Testing time-predictable earthquake recurrence by direct measurement of strain accumulation and release, Nature, 419, 287-291, 2002.

Narasimhan, B. and Srinivasan, R.: Development and evaluation of Soil Moisture Deficit Index (SMDI) and Evapotranspiration Deficit Index (ETDI) for agricultural drought monitoring, Agr. Forest Meteorol., 133, 69-88, 2005.

Neal, J., Keef, C., Bates, P., Beven, K. J., and Leedal, D.: Probabilistic flood risk mapping including spatial dependence, Hydrol. Process., 27, 1349-1363, 2013.

NERC: The Flood Studies Report (5 vols.), Natural Environment research Council: Wallingford, UK, 1975.

Neri, A., Aspinall, W. P., Cioni, R., Bertagnini, A., Baxter, P. J., Zuccaro, G., Andronico, D., Barsotti, S., Cole, P. D., Esposti Ongaro, T., Hincks, T. K., Macedonio, G., Papale, P., Rosi, M., Santacroce, R., and Woo, G.: Developing an Event Tree for Probabilistic Hazard and Risk Assessment at Vesuvius, J. Volcanol. Geotherm. Res., 178, 397-415, https://doi.org/10.1016/j.jvolgeores.2008.05.014, 2008.

Neri, A., Esposti Ongaro, T., Macedonio, G., and Gidaspow, D.: Multiparticle simulation of collapsing volcanic columns and pyroclastic flows, J. Geophys. Res. Lett., 108, 2202, https://doi.org/10.1029/2001JB000508, 2003.

Nyambayo, V. P. and Potts, D. M.: Numerical simulation of evapotranspiration using a root water uptake model, Comput. Geotech., 37, 175-186, https://doi.org/10.1016/j.compgeo.2009.08.008, 2010

Neal, J., Keef, C., Bates, P., Beven, K. J., and Leedal, D. T.: Probabilistic flood risk mapping including spatial dependence, Hydrol. Process., 27, 1349-1363, https://doi.org/10.1002/hyp.9572, 2013

Ólafsson, H. and Ágústsson, H.: The Freysnes downslope windstorm, Meteorol. Z., 16, 123-130, 2007.

Pappenberger, F., Beven, K. J., Frodsham, K., Romanovicz, R., and Matgen, P.: Grasping the unavoidable subjectivity in calibration of flood inundation models: a vulnerability weighted approach, J. Hydrol., 333, 275-287, 2007.

Paton, F. L., Maier, H. R., and Dandy, G. C.: Relative magnitudes of sources of uncertainty in assessing climate change impacts on water supply security for the southern Adelaide water supply system, Water Resour. Res., 49, 1643-1667, https://doi.org/10.1002/wrcr.20153, 2013.
Pavolonis, M. J., Feltz, W. F., Heidinger, A. K., and Gallina, G. M.: A Daytime Complement to the Reverse Absorption Technique for Improved Automated Detection of Volcanic Ash, J. Atmos. Ocean. Technol., 23, 1422-1444, 2006.

Pelley, R. E., Cooke, M. C., Manning, A. J., Thomson, D. J., Witham, C. S., and Hort, M. C.: Initial Implementation of an Inversion Technique for Estimating Volcanic Ash Source Parameters in Near Real time using Satellite Retrievals, Forecast. Res. Technical Report No: 604, Met Office, Exeter, 2015.

Penning-Rowsell, E. C.: A realistic assessment of fluvial and coastal flood risk in England and Wales, Trans. Inst. British Geogr., 40, 44-61, https://doi.org/10.1111/tran.12053, 2015.

Petley, D.: Global patterns of loss of life from landslides, Geology, 40, 927-930, https://doi.org/10.1130/G33217.1, 2012.

Pianosi, F., Beven, K., Freer, J., Hall, J. W., Rougier, J., Stephenson, D. B., and Wagener, T.: Sensitivity analysis of environmental models: A systematic review with practical workflow, Environ. Model. Softw., 79, 214-232, 2016.

Pinto, J. G., Neuhaus, C. P., Leckebusch, G. C., Reyers, M., and Kerschgens, M.: Estimation of wind storm impacts over Western Germany under future climate conditions using a statisticaldynamical downscaling approach, Tellus A, 62, 188-201, 2010.

Pinto, J. G., Gómara, I., Masato, G., Dacre, H. F., Woollings, T., and Caballero, R.: Large-scale dynamics associated with clustering of extratropical cyclones affecting Western Europe, J. Geophys. Res.-Atmos., 119, 13704-13719, 2014.

Podlaha, D., Bowen, S., Darbunyan, C., and Lörunc, M.: 2016 Annual Global Climate and Catastrophe Report, AON Benfield, available at: http://thoughtleadership.aonbenfield.com/ Documents/20170117-ab-if-annual-climate-catastrophe-report. pdf (last access: October 2018), 2017.

Potts, D. M., Dounias, G. T., and Vaughan, P. R.: Finite element analysis of progressive failure of Carsington embankment, tGéotechnique, 40, 79-101, https://doi.org/10.1680/geot.1990.40.1.79, 1990.

Prata, A. J.: Observations of volcanic ash clouds in the $10-12 \mu \mathrm{m}$ window using AVHRR/2 data, Int. J. Remote Sens., 10, 751-761, 1989.

Prata, F., Bluth, G. J. S., Rose, W. I., Schneider, D. J., and Tupper, A.: Comments on "Failures in detecting volcanic ash from a satellite-based technique”, Remote Sens. Environ., 78, 341-346, 2001.

Prudhomme, C. and Davies, H.: Assessing uncertainties in climate change impact analyses on the river flow regimes in the UK. Part 2: future climate, Clim. Change, 93, 197-222, 2009.

Prudhomme, C., Wilby, R. L., Crooks, S., Kay, A. L., and Reynard, N. S.: Scenario-neutral approach to climate change impact studies: application to flood risk, J. Hydrol., 390, 198-209, 2010

Prudhomme, C., Crooks, S., Jackson, C., Kelvin, J., and Young, A.: Future Flows, Final Technical Report, SC090016/PN9, Centre for Ecology and Hydrology, Wallingford, 2012.

Prudhomme, C., Haxton, T., Crooks, S., Jackson, C., Barkwith, A., Williamson, J., Kelvin, J., Mackay, J., Wang, L., Young, A., and Watts, G.: Future Flows Hydrology: an ensemble of daily river flow and monthly groundwater levels for use for climate change impact assessment across Great Britain, Earth Syst. Sci. Data, 5, 101-107, https://doi.org/10.5194/essd-5-101-2013, 2013. 
Ray, P. and Brown, C.: Confronting Climate Uncertainty in Water Resources Planning and Project Design - the Decision Tree Framework, World Bank Group Press, Washington, DC, 2015.

Refsgaard, J. C., Van der Sluijs, J. P., Brown, J., and Van der Keur, P.: A framework for dealing with uncertainty due to model structure error, Adv. Water Resour., 29, 1586-1597, 2006.

Refsgaard, J. C., van der Sluijs, J. P., Højberg, A. L., and Vanrolleghem, P. A.: Uncertainty in the environmental modelling process - A framework and guidance, Environ. Modell. Softw., 22, 1543-1556, 2007.

Refsgaard, J.-C., Arnbjerg-Nielsen, K., Drews, M., Halsnæs, K., Jeppesen, E., Madsen, H., Markandya, A., Olesen, J. E., Porter, J. R., and Christensen, J. H.: The role of uncertainty in climate change adaptation strategies - A Danish water management example., Mitig. Adapt. Strat. Global Change, 18, 337-359, 2013.

Renggli, D., Leckebusch, G. C., Ulbrich, U., Gleixner, S. N., and Faust, E.: The skill of seasonal ensemble prediction systems to forecast wintertime windstorm frequency over the North Atlantic and Europe, Mon. Weather Rev., 139, 3052-3068, 2011.

Ries, K. G. III, and Friesz, P. J.: Methods for estimating lowflow statistics for Massachusetts streams, U.S. Geological Survey, Water-Resources Investigations Report 00-4135, available at: http://water.usgs.gov/pubs/wri/wri004135/ (last access: October 2018), 2000.

Robine, J. M., Cheung, S. L. K., Le Roy, S., Van Oyen, H., Griffiths, C., Michel, J. P., and Herrmann, F. R.: Death toll exceeded 70,000 in Europe during the summer of 2003, Comptes Rendus Biol., 331, 171-178, 2008.

Romanowicz, R., Beven, K. J., and Tawn, J.: Bayesian calibration of flood inundation models, in: Floodplain Processes, edited by: Anderson, M. G., Walling, D. E., and Bates, P. D., 333-360, 1996.

Romanowicz, R. and Beven, K. J.: Bayesian estimation of flood inundation probabilities as conditioned on event inundation maps, Water Resour. Res., 39, W01073, https://doi.org/10.1029/2001WR001056, 2003.

Rose, W. I., Bluth, G. J. S., Schneider, D. J., Ernst, G. G. J., Riley, M., Henderson, L. J., and Mcgimsey, R. G.: Observations of Volcanic Clouds in Their First Few Days of Atmospheric Residence: The 1992 Eruptions of Crater Peak, Mount Spurr Volcano, Alas. J. Geol., 109, 677-694, 2001.

Rose, W. I., Delene, D. J., Schneider, D. J., Bluth, G. J. S., Krueger, A. J., Sprod, I. E., McKee, C., Davies, H. L., and Ernst, G. G. J.: Ice in the 1994 Rabaul eruption cloud: implications for volcano hazard and atmospheric effects, Nature, 375, 477-479, 1995.

Rosi, M., Principe, C., and Vecci, R.: The 1631 eruption of Vesuvius reconstructed from the review of chronicles and study of deposits, J. Volcanol. Geotherm. Res, 58, 151-182, 1993.

Rougier, J. and Beven, K. J.: Model limitations: the sources and implications of epistemic uncertainty, in: Risk and uncertainty assessment for natural hazards, edited by: Rougier, J., Sparks, S., and Hill, L., Cambridge University Press: Cambridge, UK, 4063, 2013.

Rougier, J., Sparks, S., and Hill, L.: Risk and uncertainty assessment for natural hazards, Cambridge University Press: Cambridge, UK, 2013.

Rubio, E., Hall, J. W., and Anderson, M. G.: Uncertainty analysis in a slope hydrology and stability model using probabilistic and imprecise information, Comput. Geotech., 31, 529-536, 2004.
Samaniego, L., Kumar,R., and Zink, M.: Implications of Parameter Uncertainty on Soil Moisture Drought Analysis in Germany, J. Hydrometeor., 14, 47-68, 2013.

Sampson, C. C., Fewtrell, T. J., Duncan, A., Shaad, K., Horritt, M. S., and Bates, P. D.: Using terrestrial laser scanning data to drive decimetric resolution urban inundation models, Adv. Water Resour., 41, 1-17, https://doi.org/10.1016/j.advwatres.2012.02.010, 2012.

Sansom, P. G., Stephenson, D. B., Ferro, C. A., Zappa, G., and Shaffrey, L.: Simple uncertainty frameworks for selecting weighting schemes and interpreting multimodel ensemble climate change experiments, J. Climate, 26, 4017-4037, 2013.

Satake, K., Wang, K., and Atwater, B. F.: Fault slip and seismic moment of the 1700 Cascadia earthquake inferred from Japanese tsunami descriptions, J. Geophys. Res.-Solid Earth, 108, 2535, https://doi.org/10.1029/2003JB002521, 2003.

Savage, J. T. S., Pianosi, F., Bates, P. D., Freer, J., and Wagener, T.: Quantifying the importance of spatial resolution and other factors through global sensitivity analysis of a flood inundation model, Water Resour. Res., 52, 9146-9163, https://doi.org/10.1002/2015WR018198, 2016.

Sayers, P. B., Hall, J. W., and Meadowcroft, I. C.: Towards riskbased flood hazard management in the UK, Proceedings of the ICE-Civil Engineering, 150, 36-42, 2002.

Schmehl, K. J., Haupt, S. E., and Pavolonis, M. J.: A Genetic Algorithm Variational Approach to Data Assimilation and Application to Volcanic Emissions, Pure Appl. Geophys., 169, 519-537, 2011.

Schwierz, C., Köllner-Heck, P., Mutter, E. Z., Bresch, D. N., Vidale, P. L., Wild, M., and Schär, C.: Modelling European winter wind storm losses in current and future climate, Clim. Change, 101, 485-514, 2010.

Sene, K., Weerts, A. H., Beven, K. J., Moore, R. J., Whitlow, C., Laeger, S., and Cross, R.: Uncertainty estimation in fluvial flood forecasting applications, in: Applied Uncertainty Analysis for Flood Risk Management, edited by: Beven, K. J. and Hall, J. W., Imperial College Press: London, 462-498, 2014.

Shen, Z. K., Sun, J., Zhang, P., Wan, Y., Wang, M., Bürgmann, R., Zeng, Y., Gan, W., Liao, H., and Wang, Q.: Slip maxima at fault junctions and rupturing of barriers during the 2008 Wenchuan earthquake, Nat. Geosci., 2, 718-724, 2009.

Shimazaki, K. and Nakata, T.: Time predictable recurrence for large earthquakes, Geophys. Res. Lett., 7, 279-282, 1980.

Simpson, J. J., Hufford, G., Pieri, D., and Berg, J.: Failures in detecting volcanic ash from a satellite-based technique, Remote Sens. Environ., 72, 191-217, 2000.

Simpson, M., James, R., Hall, J.W., Borgomeo, E., Ives, M. C., Almeida, S., Kingsborough, A., Economou, T., Stephenson, D., and Wagener, T.: Decision analysis for management of natural hazards, Ann. Rev. Environ. Resour., 41, 489-516, https://doi.org/10.1146/annurev-environ-110615-090011, 2016.

Singh, R., Wagener, T., Crane, R., Mann, M. E., and Ning, L.: A vulnerability driven approach to identify adverse climate and land use change combinations for critical hydrologic indicator thresholds - Application to a watershed in Pennsylvania, USA, Water Resour. Res., 50, 3409-3427, https://doi.org/10.1002/2013WR014988, 2014.

Skarlatoudis, A. A., Somerville, P. G., Thio, H. K., and Bayless, J. R.: Broadband strong ground motion simulations of large sub- 
duction earthquakes, B. Seismol. Soc. Am., 105, 3050-3067, 2015.

Smith, P. J., Beven, K. J., Weerts, A. H., and Leedal, D.: Adaptive correction of deterministic models to produce probabilistic forecasts, Hydrol. Earth Syst. Sci., 16, 2783-2799, https://doi.org/10.5194/hess-16-2783-2012, 2012.

Smith, P. J., Beven, K. J., and Horsburgh, K.: Data Based Mechanistic modelling of tidally affected river reaches for flood warning purposes: An example on the River Dee, UK, Q. J. Roy. Meteor. Soc., 139, 340-349, https://doi.org/10.1002/qj.1926, $2013 a$.

Smith, P. J., Panziera, L., and Beven, K. J.: Forecasting flash floods using Data Based Mechanistic models and NORA radar rainfall forecasts, Hydrol. Sci. J., 59, 1403-1417, https://doi.org/10.1080/02626667.2013.842647, 2013b.

Sparks, R. S. J.: The dimensions and dynamics of volcanic eruption columns, Bull. Volcanol., 48, 3-15, 1986.

Sparks, R. S. J., Bursik, M. I., Carey, S. N., Gilbert, J. S., Glaze, L. S., Sigurdsson, H., and Woods, A. W.: Volcanic Plumes, John Wiley \& Sons, Chichester, UK, 1997.

Stafford, P. J.: Crossed and nested mixed-effects approaches for enhanced model development and removal of the ergodic assumption in empirical ground-motion models, B. Seismol. Soc. Am., 104, 702-719, 2014.

Stein, S., Geller, R. J., and Liu, M.: Why earthquake hazard maps often fail and what to do about it, Tectonophysics, 562, 1-25, 2012.

Stein, S. and Stein, J. L.: Shallow versus deep uncertainties in natural hazard assessments, EOS Trans. Am. Geophys. Un., 94, 133134, 2013.

Stevenson, J. A., Millington, S. C., Beckett, F. M., Swindles, G. T., and Thordarson, T.: Big grains go far: understanding the discrepancy between tephrochronology and satellite infrared measurements of volcanic ash, Atmos. Meas. Tech., 8, 2069-2091, https://doi.org/10.5194/amt-8-2069-2015, 2015.

Stohl, A., Prata, A. J., Eckhardt, S., Clarisse, L., Durant, A., Henne, S., Kristiansen, N. I., Minikin, A., Schumann, U., Seibert, P., Stebel, K., Thomas, H. E., Thorsteinsson, T., Tørseth, K., and Weinzierl, B.: Determination of time- and height-resolved volcanic ash emissions and their use for quantitative ash dispersion modeling: the 2010 Eyjafjallajökull eruption, Atmos. Chem. Phys., 11, 4333-4351, https://doi.org/10.5194/acp-114333-2011, 2011.

Svensson, C. and Jones, D. A.: Dependence between sea surge, river flow and precipitation in south and west Britain, Hydrol. Earth Syst. Sci., 8, 973-992, https://doi.org/10.5194/hess-8-973-2004, 2004.

Sykes, L. R. and Menke, W.: Repeat times of large earthquakes: implications for earthquake mechanics and long-term prediction, B. Seismol. Soc. Am., 96, 1569-1596, 2006.

Taddeucci, J., Scarlato, P., Montanaro, C., Cimarelli, C., Del Bello, E., Freda, C., Andronico, D., Gudmundsson, M. T., and Dingwell, D. B.: Aggregation-dominated ash settling from the Eyjafjallajökull volcanic cloud illuminated by field and laboratory high-speed imaging, Geology, 39, 891-894, 2011.

Tappin, D. R., Grilli, S. T., Harris, J. C., Geller, R. J., Masterlark, T., Kirby, J. T., Shi, F., Ma, G., Thingbaijam, K. K. S., and Mai, P. M.: Did a submarine landslide contribute to the 2011 Tohoku tsunami?, Mar. Geol., 357, 344-361, 2014.
Tesfamariam, S. and Goda, K.: Handbook of Seismic Risk Analysis and Management of Civil Infrastructure Systems, Woodhead Publishing Ltd., Cambridge, United Kingdom, 884 p., 2013.

Thio, H. K., Somerville, P., and Ichinose, G.: Probabilistic analysis of strong ground motion and tsunami hazards in southeast Asia, J. Earthq. Tsunami, 1, 119-137, 2007.

Tiampo, K. F., Rundle, J. B., Klein, W., Holliday, J., Sá Martins, J. S., and Ferguson, C. D.: Ergodicity in natural earthquake fault networks, Phys. Rev. E, 75, 066107, https://doi.org/10.1103/PhysRevE.75.066107, 2007.

Tomkins, K. M.: Uncertainty in streamflow rating curves: methods, controls and consequences, Hydrol. Process., 28, 464-481, https://doi.org/10.1002/hyp.9567, 2014.

UNISDR: Global Assessment Report on Disaster Risk Reduction, Making Development Sustainable: The Future of Disaster Risk Management (Geneva: United Nations), available at: www.preventionweb.net/english/hyogo/gar/2015/en/gar-pdf/ GAR2015_EN.pdf (last access: 11 September 2018), 2015.

Van der Sluijs, J. P., Craye, M., Funtowicz, S., Kloprogge, P., Ravetz, J., and Risbey, J.: Combining quantitative and qualitative measures of uncertainty in model-based environmental assessment: the NUSAP system, Risk Anal., 25, 481-492, 2005.

van Gelder, P. and Vrijling, H.: Flood defence reliability analysis, in: Applied Uncertainty Analysis for Flood Risk Management, edited by: Beven, K. J. and Hall, J. W., Imperial College Press: London, 270-296, 2014.

Van Loon, A. F., Stahl, K., Di Baldassarre, G., Clark, J., Rangecroft, S., Wanders, N., Gleeson, T., Van Dijk, A. I. J. M., Tallaksen, L. M., Hannaford, J., Uijlenhoet, R., Teuling, A. J., Hannah, D. M., Sheffield, J., Svoboda, M., Verbeiren, B., Wagener, T., and Van Lanen, H. A. J.: Drought in a humanmodified world: reframing drought definitions, understanding, and analysis approaches, Hydrol. Earth Syst. Sci., 20, 36313650, https://doi.org/10.5194/hess-20-3631-2016, 2016a.

Van Loon, A. F., Gleeson, T., Clark, J., Van Dijk, A. I., Stahl, K., Hannaford, J., Di Baldassarre, G., Teuling, A. J., Tallaksen, L. M., Uijlenhoet, R., and Hannah, D. M.: Drought in the Anthropocene, Nat. Geosci., 9, 89-91, https://doi.org/10.1038/ngeo2646 2016 b.

Vitolo, R., Stephenson, D. B., Cook, I. M., and Mitchell-Wallace, K.: Serial clustering of intense European storms, Meteorol. Z., $18,411-424,2009$.

Vogel, A.: The bibliography of the history of dam failures - an event based accident data collection, P. Europ. Safety Reliab. Conference, 2, 1361-1366, 2001.

Wagener, T., Wheater, H. S., and Gupta, H. V.: Rainfall-runoff modelling in gauged and ungauged catchments, World Scientific Press, UK, 2004.

Wagener, T. and Gupta, H. V.: Model identification for hydrological forecasting under uncertainty, Stoch. Environ. Res. Risk Assess., 19, 378-387, https://doi.org/10.1007/s00477-005-0006-5, 2005.

Wagener, T. and Wheater, H. S.: Parameter estimation and regionalization for continuous rainfall-runoff models including uncertainty, J. Hydrol., 320, 132-154, 2006.

Walker, G.: A critical examination of models and projections of demand in water utility resource planning in England and Wales, Int. J. Water Resour. Develop., 29, 352-372, 2012.

Walker, W. E., Harremoës, P., Rotmans, J., Van der Sluijs, J. P., Van Asselt, M. B. A., Janssen, P., and Krayer von Krauss, M. P.: 
Defining Uncertainty A Conceptual Basis for Uncertainty Management in Model-Based Decision, Support, Integr. Assess., 4, 5-17, 2003.

Warmink, J. J., Janssen, J. A. E. B., Booij, M. J., and Krol, M. S.: Identification and classification of uncertainties in the application of environmental models, Environ. Modell. Softw., 25, 1518$1527,2010$.

Webster, H. N., Thomson, D. J., Johnson, B. T., Heard, I. P. C., Turnbull, K., Marenco, F., Kristiansen, N. I., Dorsey, J., Minikin, A., Weinzierl, B., Schumann, U., Sparks, R. S. J., Loughlin, S. C., Hort, M. C., Leadbetter, S. J., Devenish, B. J., Manning, A. J., Witham, C. S., Haywood, J. M., and Golding, B. W.: Operational prediction of ash concentrations in the distal volcanic cloud from the 2010 Eyjafjallajökull eruption, J. Geophys. Res., 117, D00U08, https://doi.org/10.1029/2011JD016790, 2012.

Western, L. M., Watson, M., and Francis, P.: Uncertainty in two-channel infrared remote sensing retrievals of a wellcharacterised volcanic ash cloud, Bull. Volcanol., 77, 67, https://doi.org/10.1007/s00445-015-0950-y, 2015.

Wilby, R. L. and Dessai, S.: Robust adaptation to climate change, Weather, 65, 180-185, 2010.

Wilby, R. L. and Harris, I.: A framework for assessing uncertainties in climate change impacts: Low-flow scenarios for the River Thames, UK, Water Resour. Res., 42, W02419, https://doi.org/10.1029/2005WR004065,2006.

Wilkins, K. L., Mackie, S., Watson, I. M., Webster, H. N., Thomson, D. J., and Dacre, H. F.: Data insertion in volcanic ash cloud forecasting, Ann. Geophys., 57, 1-6, 2014.

Wilkins, K. L., Watson, I. M., Kristiansen, N. I., Dacre, H. F., Webster, H. N., Thomson, D. J., and Prata, A. J.: Using data insertion with the NAME model to simulate the 8 May 2010 Eyjafjallajökull volcanic ash cloud, J. Geophys. Res.-Atmos., 121, 306323, 2016.

Winsemius, H. C., Aerts, J. C. J. H., van Beek, L. P. H., Bierkens, M. F. P., Bouwman, A, Jongman, B., Kwadijk, J. C. J., Ligtvoet, W., Lucas, P. L., van Vuuren, D. P., and Ward, P. J.: Global drivers of future river flood risk, Nat. Clim. Change, 6, 381-385, 2016.

Woo, G.: Calculating catastrophe, Imperial College Press, London, UK, 2011.

Woo, G. and Aspinall, W. P.: Thirty-Year Bayesian Updating of PSHA for Hinkley Point NPP. Paper presented to CSNI Workshop on "Testing PSHA Results and Benefit of Bayesian Techniques for Seismic Hazard Assessment”, 4-6 February 2015, Eucentre Foundation, Pavia, Italy; 13 pp., 2015.
Wood, M., Hostache, R., Neal, J., Wagener, T., Giustarini, L., Chini, M., Corato, G., Matgen, P., and Bates, P.: Calibration of channel depth and friction parameters in the LISFLOOD-FP hydraulic model using medium-resolution SAR data and identifiability techniques, Hydrol. Earth Syst. Sci., 20, 4983-4997, https://doi.org/10.5194/hess-20-4983-2016, 2016.

Woodhouse, M. J., Hogg, A. J., Phillips, J. C., and Sparks, R. S. J.: Interaction between volcanic plumes and wind during the 2010 Eyjafjallajökull eruption, Iceland, J. Geophys. Res.-Solid Earth, 118, 92-109, 2013.

Wu, T. H. and Abdel-Latif, M. A.: Prediction and mapping of landslide hazard, Canad. Geotech. J., 37, 781-795, https://doi.org/10.1139/cgj-37-4-781, 2000.

Xia, J., Lin, B., Falconer, R. A., and Wang, G.: Modelling dambreak flows over mobile beds using a 2D coupled approach, Adv. Water Resour., 33, 171-183, 2010.

Yatheendradas, S., Wagener, T., Gupta, H.V., Schaeffer, M., Unkrich, K., and Goodrich, D.: Sensitivity analysis and calibration of a distributed semi-arid hydrologic model for flash flood forecasting, Water Resour. Res., 44, W05S19, https://doi.org/10.1029/2007WR005940, 2008.

Yeo, G. L. and Cornell, C. A.: A probabilistic framework for quantification of aftershock ground-motion hazard in California: methodology and parametric study, Earthquake Eng. Struct. Dyn., 38, 45-60, 2009.

Young, P. C., Romanowicz, R. J., and Beven, K. J.: A data-based mechanistic modelling approach to real-time flood forecasting, in: Applied Uncertainty Analysis for Flood Risk Management, edited by: Beven, K. J. and Hall, J. W., Imperial College Press: London, 407-461, 2014.

Zappa, G., Shaffrey, L. C., and Hodges, K. I.: The Ability of CMIP5 Models to Simulate North Atlantic Extratropical Cyclones, J. Climate, 26, 5379-5396, 2013.

Zuccolo, E., Vaccari, F., Peresan, A., and Panza, G. F.: Neodeterministic and probabilistic seismic hazard assessments: a comparison over the Italian territory, Pure Appl. Geophys., 168, 69-83, 2011. 